\title{
Dynamic Analysis and Design Optimization of Series Hydraulic Hybrid System through Power Bond Graph Approach
}

\author{
R. Ramakrishnan, Somashekhar S. Hiremath, and M. Singaperumal \\ Precision Engineering and Instrumentation Laboratory, Department of Mechanical Engineering, \\ Indian Institute of Technology Madras, Chennai-600036, India \\ Correspondence should be addressed to Somashekhar S. Hiremath; somashekhar@iitm.ac.in
}

Received 30 September 2013; Revised 25 December 2013; Accepted 26 December 2013; Published 1 April 2014

Academic Editor: Tang-Hsien Chang

Copyright (C) 2014 R. Ramakrishnan et al. This is an open access article distributed under the Creative Commons Attribution License, which permits unrestricted use, distribution, and reproduction in any medium, provided the original work is properly cited.

\begin{abstract}
The availability of natural gas and crude oil resources has been declining over the years. In automobile sector, the consumption of crude oil is $63 \%$ of total crude oil production in the world. Hence, automobile industries are placing more emphasis on energy efficient hydraulic hybrid systems, which can replace their conventional transmission systems. Series hydraulic hybrid system (SHHS) is a multidomain mechatronics system with two distinct power sources that includes prime mover and hydropneumatic accumulator. It replaces the conventional transmission system to drive the vehicle. The sizing of the subsystems in SHHS plays a major role in improving the energy efficiency of the vehicle. In this paper, a power bond graph approach is used to model the dynamics of the SHHS. The obtained simulation results indicate the energy flow during various modes of operations. It also includes the dynamic response of hydropneumatic accumulator, prime mover, and system output speed. Further, design optimization of the system is carried out to optimize the process parameters for maximizing the system energy efficiency. This leads to increase in fuel economy and environmentally friendly vehicle.
\end{abstract}

\section{Introduction}

The transportation sector consumes $63 \%$ of world crude oil production and causes $17 \%$ of total environmental pollution across the world. In this scenario, high cost and shortage of crude oil have created a need for energy saving, efficient, and environmental friendly transport system [1]. To mitigate this situation, a hybrid system technology was adopted to develop an energy efficient transportation vehicle. This system consists of two distinct power sources and kinetic energy recovery technology, which makes this technology a potential solution for the design of energy efficient transmission. The possible combinations of two distinct power sources are gasoline/hydraulic (hydraulic hybrid), gasoline/electric (electric hybrid), and fuel cell/battery (fuel cell hybrid). Typically, one source converts the fuel into energy and another source is a storage unit. During mechanical friction braking in a conventional vehicle, kinetic energy in the wheel is lost as heat energy. However, hybrid system has the capability to regenerate the kinetic energy into useful energy through a method called regenerative braking. Thus, the hybrid systems turn out to be a hot topic for researchers in automotive companies and research institutes all over the world $[2,3]$.

Generally, these systems can be classified into two categories-electric hybrids and hydraulic hybrids. The electric hybrid system is the most common and commercially available hybrid system in the market such as Honda Insight, Toyota Prius, Ford Escape, and so forth. An electric battery is a major sub-subsystem in an electric hybrid vehicle, which stores the regenerated energy and delivers the same energy during acceleration of the vehicle $[4,5]$. In the electric system, the round-trip efficiency for the battery is about $81 \%$, whereas the round-trip efficiency for a hydropneumatic accumulator is $94 \%$ which has been proven by Parker Hannifin in their Cumulo systems [6]. As per the higher round-trip efficiency of the energy storage devices, the energy recovering efficiency of hydraulic system is improved to $63 \%$ when compared to $53 \%$ in electrical system. Hydropneumatic accumulator in a hydraulic hybrid possesses very high power density and quick charging capability of regenerated energy, when compared to its counterparts. Therefore, this characteristic in the operation of accumulator is utilized in high power requirement 
applications such as heavy vehicles and construction and agriculture machinery. The hydropneumatic accumulator has relatively poor energy density in comparison with a battery [7]. However, sizing of hydropneumatic accumulator in hydraulic hybrid dictates the energy density or energy storage capability of accumulator.

As per the literature, hydraulic hybrid systems are classified based on configurations into two systems, namely, parallel and series hydraulic hybrid system as shown in Figure 1 [8-10]. In parallel hydraulic hybrid system, the power from the prime mover takes a parallel path via mechanical transmission as well as hydraulic transmission to reach the output shaft as shown in Figure 1(a). These systems have better power transmission efficiency, but it has poor controllability on power distribution in the system due to transmission of power in two different domains [11]. On the other hand, the system input power to the series hydraulic hybrid takes purely a hydraulic domain of power transmission as shown in Figure 1(b). Independent control of the wheels in series configuration provides better controllability aspect when compared to parallel configuration [12].

SHHS in a vehicle is propelled by a system, which includes subsystems such as prime mover (gasoline engine), hydraulic motor/pump, and hydropneumatic accumulators in series configuration as shown in Figure 1(b). During braking mode of the vehicle, hydraulic regeneration pump converts the kinetic energy in the wheel into useful hydraulic energy through hydraulic regenerative braking and the regenerated energy is stored in the high-pressure hydropneumatic accumulator. The energy efficiency of the vehicle is enhanced by using the stored regenerated energy in the accumulator to power hydraulic traction motor during the subsequent acceleration of the vehicle [13]. There is plenty of literature focused on parallel hydraulic hybrid systems but the literatures devoted to series hydraulic hybrid systems are limited and an overview is provided in the following paragraphs.

A modeling methodology for hybrid vehicle was proposed in 1997 and then a computer model of SHHS was developed and investigations focused only on urban passenger vehicle. This study shows that hydraulic hybrid power train is a feasible concept and fuel economy in addition to emission reduction can be done considerably [14]. Filipi and Kim developed hydraulic hybrid propulsion for heavy duty vehicles which combines both simulation and engine in the loop techniques to maximize fuel economy and emission benefits [15]. Ramakrishnan et al. [16] developed theoretical model to investigate the effect of various system parameters such as volumetric displacement of regeneration pump, precharge pressure of accumulator on the system output power in series hydraulic hybrid system with hydrostatic regenerative braking. Figure 2 shows the comparative study made between Filipi and Kim and Ramakrishnan et al. series hybrid configuration. Figure 2(a) shows the driving cycle used for the Filipi and Kim configuration and Figure 2(b) show the corresponding simulation results of the output power variation. The developed model was compared with Filipi and Kim model by inputting the same driving cycle as shown in Figure 2(a). It was observed that the developed system shows drastic improvement in output power. The simulation result using this driving cycle for the proposed system is shown in Figure 2(c). Comparison of Figure 2(b) and Figure 2(c) shows that output power of the proposed SHHS is higher than the output power delivered by Filipi and Kim configuration. The proposed system shows better ability to deliver the power during the acceleration phase (165th second to 205th second) and during the hydraulic regenerative braking (278th second to 330th second). In view of a better energy management control strategy, the system incorporates an accumulator centric control strategy to manage the power based on state of charge of accumulator and control the hydraulic energy delivered from the accumulator.

The system parameters like accumulator volume and system pressure of hydraulic hybrid driveline are optimized. A control strategy for passenger cars based on dividing the accumulator volume into two parts, one for regeneration and the other for road decoupling, has been proposed by Wu et al. [17]. The main target of researchers is to obtain optimum engine speed for a list of different control parameters in the system like angular velocity and torque combinations. A parametric study on hybrid vehicle as discussed by Sinoquet et al. [18] focused on variations of the size of the power train components and optimization of the power split between the prime mover and electric motor with respect to fuel consumption. It was reported that system parameters are effectively decided using design optimization. On the other hand, researches pertaining to design optimization of hydraulic hybrid system are meager. In this paper, a power bond graph approach is used to model the dynamics of a series hydraulic hybrid system. The simulation results analyze the various modes of operation, dynamic response of hydr-pneumatic accumulator, prime mover, and system output speed. Further, a design optimization of the system is carried out to maximize the system energy efficiency. This leads to increase in fuel economy and environmentally friendly vehicle.

\section{Series Hydraulic Hybrid System}

The proposed configuration of the SHHS is as shown in Figure 3. The major subsystems of SHHS are a prime mover, a master hydraulic pump, a hydraulic traction motor, a hydraulic regeneration pump, and a hydropneumatic accumulator arranged in a series configuration. The master hydraulic pump coupled with prime mover acts as the hydraulic power source, which converts the mechanical energy into hydraulic energy. According to the operating mode, master hydraulic pump and hydropneumatic accumulator power the hydraulic traction motor. The hydraulic regeneration pump and the hydraulic traction motor are connected to the wheel through a differential gear box unit. The description of the other components such as hydraulic hose, gearbox, hydraulic tank, pressure relief valve, and nonreturn valve in the circuit and the operation methodology are detailed in the earlier work of the authors [19].

The working principle of SHHS is as shown in Figure 4. The system is divided into three operating modes, namely, acceleration mode, cruising mode, and braking mode of the vehicle. 


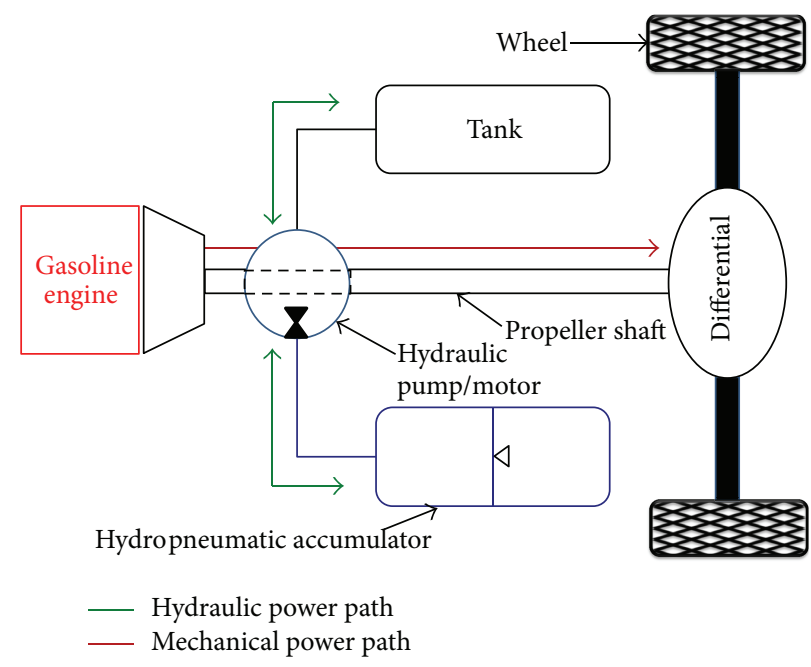

(a)

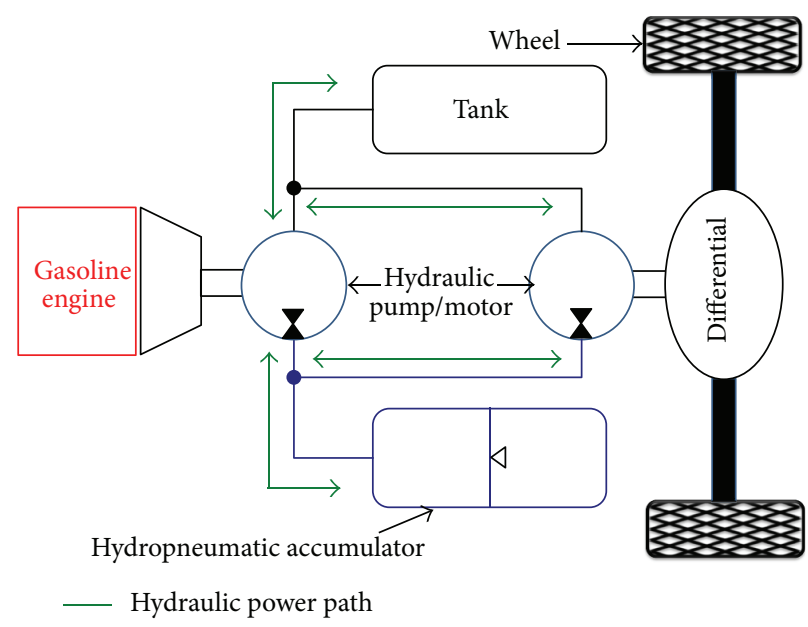

(b)

FIgURE 1: Hybrid configuration, (a) parallel hydraulic and (b) series hydraulic.

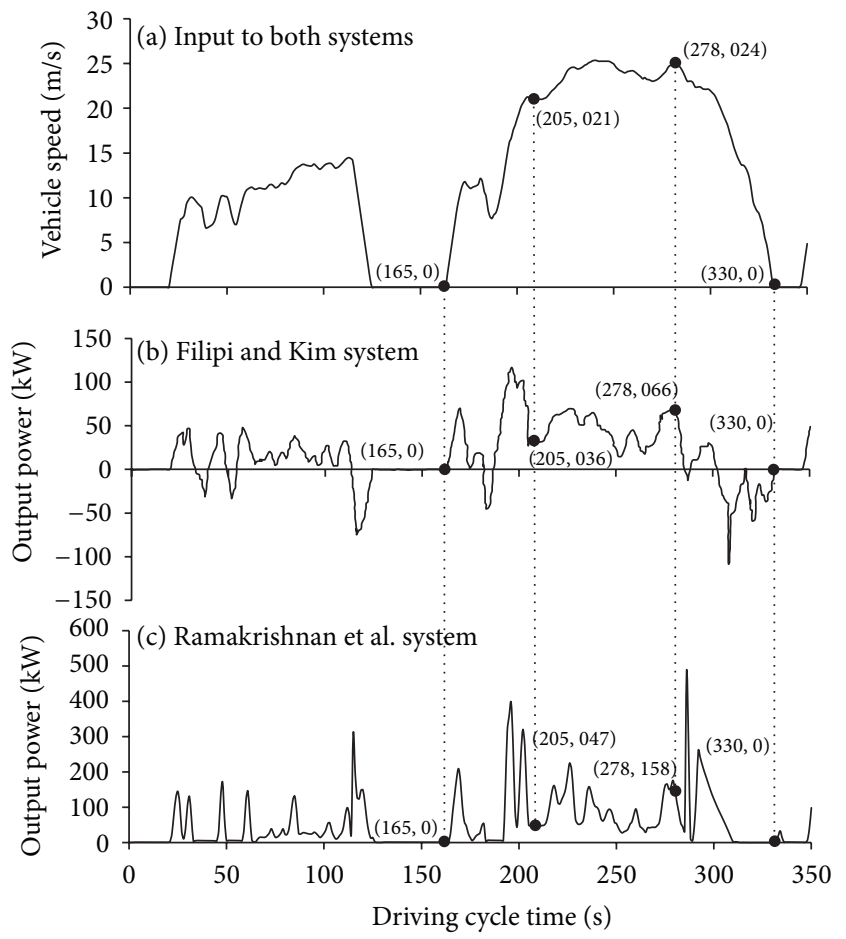

FIgURE 2: Comparative study between Filipi and Kim [15] and Ramakrishnan et al. [16] systems.

(i) When the vehicle is in acceleration mode, energy from two power sources (prime mover and hydropneumatic accumulator) are used to propel the vehicle; that is, hydraulic energy from two sources are supplied simultaneously to power the hydraulic traction motor.

(ii) During the cruising mode of the vehicle, hydraulic energy from hydropneumatic accumulator is cutoff and the power from the prime mover is only used to drive the vehicle. The volumetric flow rate from the master hydraulic pump is varied by changing the speed of the prime mover like BLDC servomotor. Therefore, the speed of the traction hydraulic motor or velocity of the vehicle is varied by change in hydraulic volumetric flow rate from the master hydraulic pump to the traction hydraulic motor.

(iii) In the braking mode, hydraulic energy from prime mover and hydropneumatic accumulator is cutoff. An energy recovery method called hydraulic regenerative braking through displacement factor control is proposed in this work. Displacement factor control method is an energy recovery process in which the controller adjusts the displacement factor of servo-controlled variable displacement hydraulic regeneration pump and the pumping cycle starts. As a result, the applied torque or load on the hydraulic traction motor increases. Thus, hydraulic regenerative braking offers resistance to the wheel rotation in braking of the vehicle. In addition to that, this method converts kinetic energy in the wheels (usually lost as heat energy due to mechanical friction braking) into useful hydraulic energy. Once the accumulator is charged with hydraulic energy through hydraulic regenerative braking, potential energy stored in the accumulator will increase the SoC level in the accumulator, which can be used in the next acceleration cycle.

An accumulator centric energy management control strategy is used to control the control variables such as input speed of the prime mover, flow rate from the accumulator, and displacement factor for hydraulic regenerative braking. As per this strategy, flow rate into and out of the accumulator is decided by these three factors and they are regenerative braking energy, instantaneous state of charge (SoC) of the accumulator and power requirement. During acceleration of the vehicle, the controller will operate the prime mover in the high efficiency region and control the hydraulic flow from the accumulator through proportional control valve to run traction motor until low SoC point or level is reached. Beyond this point, the prime mover will supply the energy to the vehicle in constant velocity mode. 


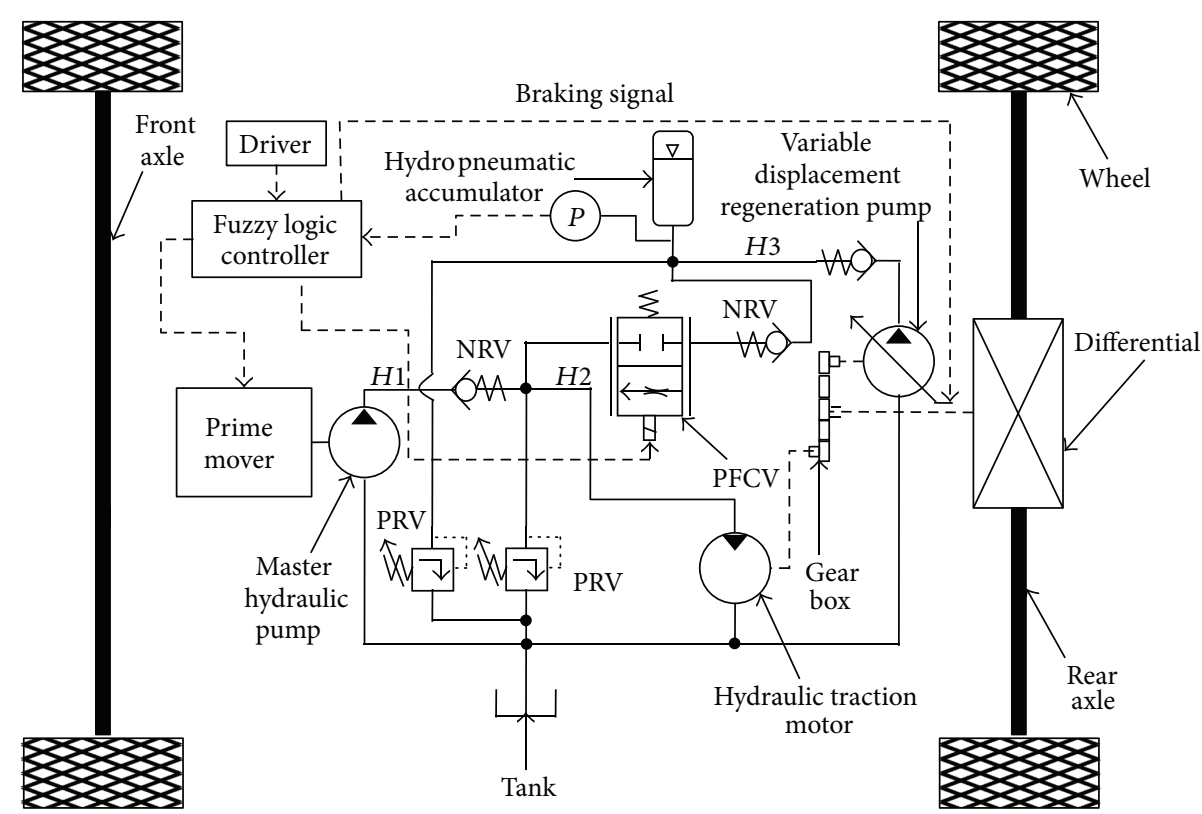

FIgURE 3: Configuration of series hydraulic hybrid system [19].

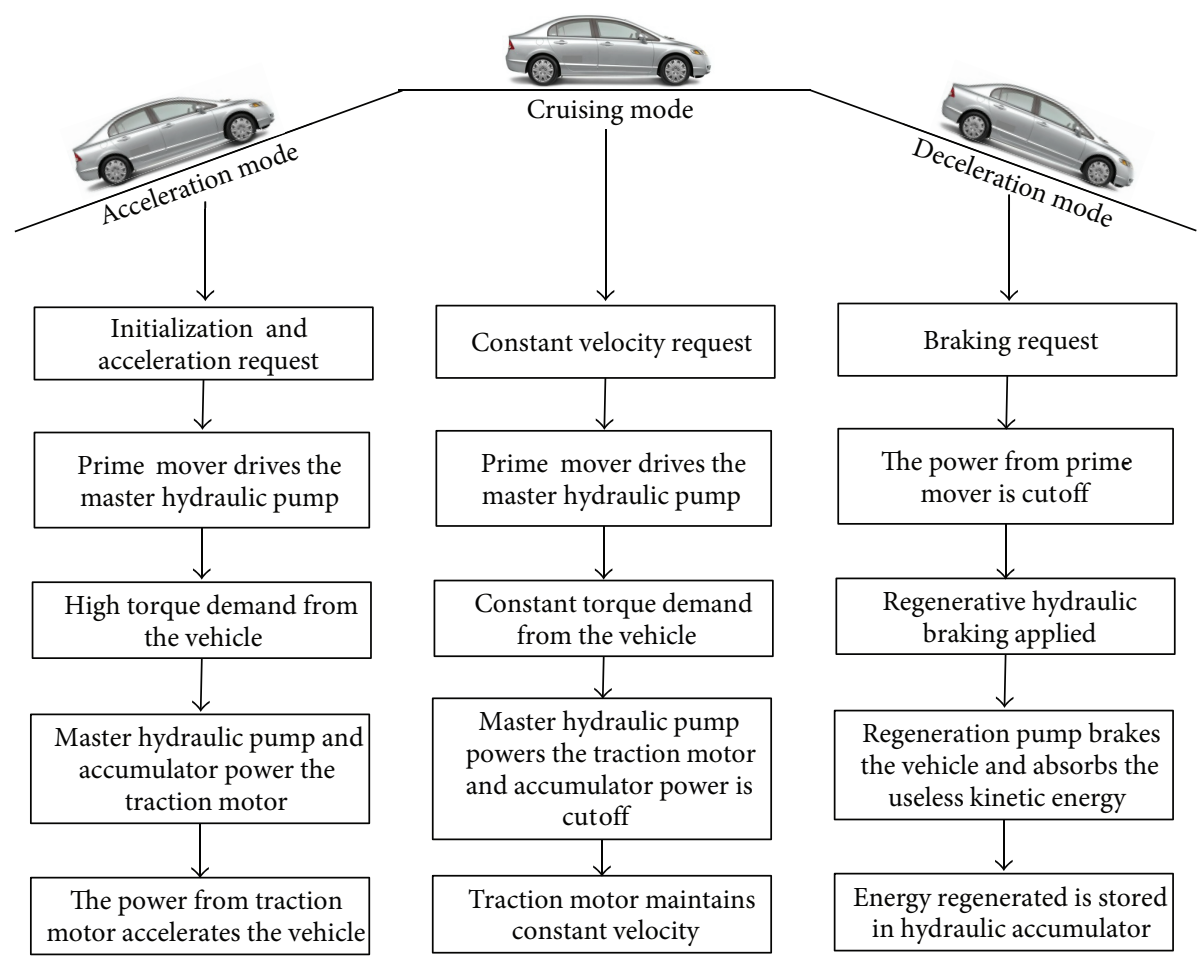

FIGURE 4: Working principle of series hydraulic hybrid system.

\section{Modeling of System Dynamics}

Modeling of system dynamics involves obtaining a mathematical form of description to predict the dynamic behavior of a system in terms of physical variables. Despite the differences in the physical variables used to characterize the systems in various disciplines, certain fundamental similarities exist. Exploiting these similarities in a defined manner, the task of modeling is simplified and our overall insight into the dynamic performance of physical systems is increased [21]. Energy is the unified concept in this approach. Thus, power bond graph modeling procedure would be appropriate for modeling the dynamics of series hydraulic hybrid system, where energy flow during various operating modes is of common interest.

Bond graph is a powerful tool to model a system involving mechanical, hydraulics, thermal, and electrical elements such as the hydraulic hybrid system. The SHHS is a multidomain, 
TABLE 1: Effort and flow in various domains.

\begin{tabular}{lcc}
\hline Domains & Effort $(e)$ & Flow $(f)$ \\
\hline Electrical & Voltage, $(\mathrm{V})$ & Current, $(\mathrm{A})$ \\
Mechanical & & \\
Translational & Force, $(\mathrm{N})$ & Velocity, $(\mathrm{m} / \mathrm{s})$ \\
Rotational & Torque, $(\mathrm{Nm})$ & Angular velocity, $(\mathrm{rad} / \mathrm{s})$ \\
Hydraulic & Pressure, $(\mathrm{Pa})$ & Volumetric flow, $\left(\mathrm{m}^{3} / \mathrm{s}\right)$ \\
\hline
\end{tabular}

nonlinear mechatronics system, which consists of several physical and process parameters like accumulator size, initial accumulator gas pressure, accumulator precharge pressure, master hydraulic pump-displacement, hydraulic regeneration pump-displacement, and hydraulic traction motordisplacement [22]. The design of these parameters is a complex and tedious process. Therefore, an optimization procedure has to be adopted in order to decide the system parameters by satisfying the essential objective functions. To optimize such a physical system, a mathematical model representing the physical system under consideration is essential. Hence, bond graph modeling technique is used to model the nonlinear multidomain dynamic SHHS.

3.1. Power Bond Graph Approach . Bond graph modeling is a graphical, computer aided modeling methodology that is particularly suited for the concurrent design of multidisciplinary systems or engineering systems like mechanical, electrical, hydraulic, or pneumatic components, including interactions of physical effects from various energy domains [23]. In a bond graph model, a physical system is represented by basic passive elements that are able to interchange power: resistance $(R)$, capacitance $(C)$, and inertia $(I)$ [24]. As energy can flow back and forth between two power ports of different nodes, a half arrow is added to each bond indicating a reference direction of the energy flow. Furthermore, it is a useful modeling construct to represent the amount of power, $P(t)$, at each time, $t$, by the product of two conjugate variables, which are called effort, $e$, and flow, $f$, respectively $[25,26]$.

Table 1 lists the effort and flow variables in the various domains [27]. After the system is represented by bond graph elements, the next step consists of assigning the power bonds and active bonds between elements. Power bonds are assigned according to the direction of positive power flow. This power convention can be set arbitrarily. Once the power bonds are assigned, causality must be established within the bond graph. This causality analysis is determined by rules described in bond graph theory [28]. Causality in bond graph model is indicated with a vertical stroke at the start or end of the bond arrow to define the power components direction, that is, effort and flow direction. A causal stroke located at the end of a power bond indicated that effort is the driving force to the element, while a stroke located at the beginning of the bond indicates that flow is the input to the element $[29,30]$. Causality of each type of element is summarized in Table 2.

3.2. System Modeling. The various subsystems such as the master hydraulic pump, traction hydraulic motor, hydraulic
TABLE 2: Causality for bond graph elements.

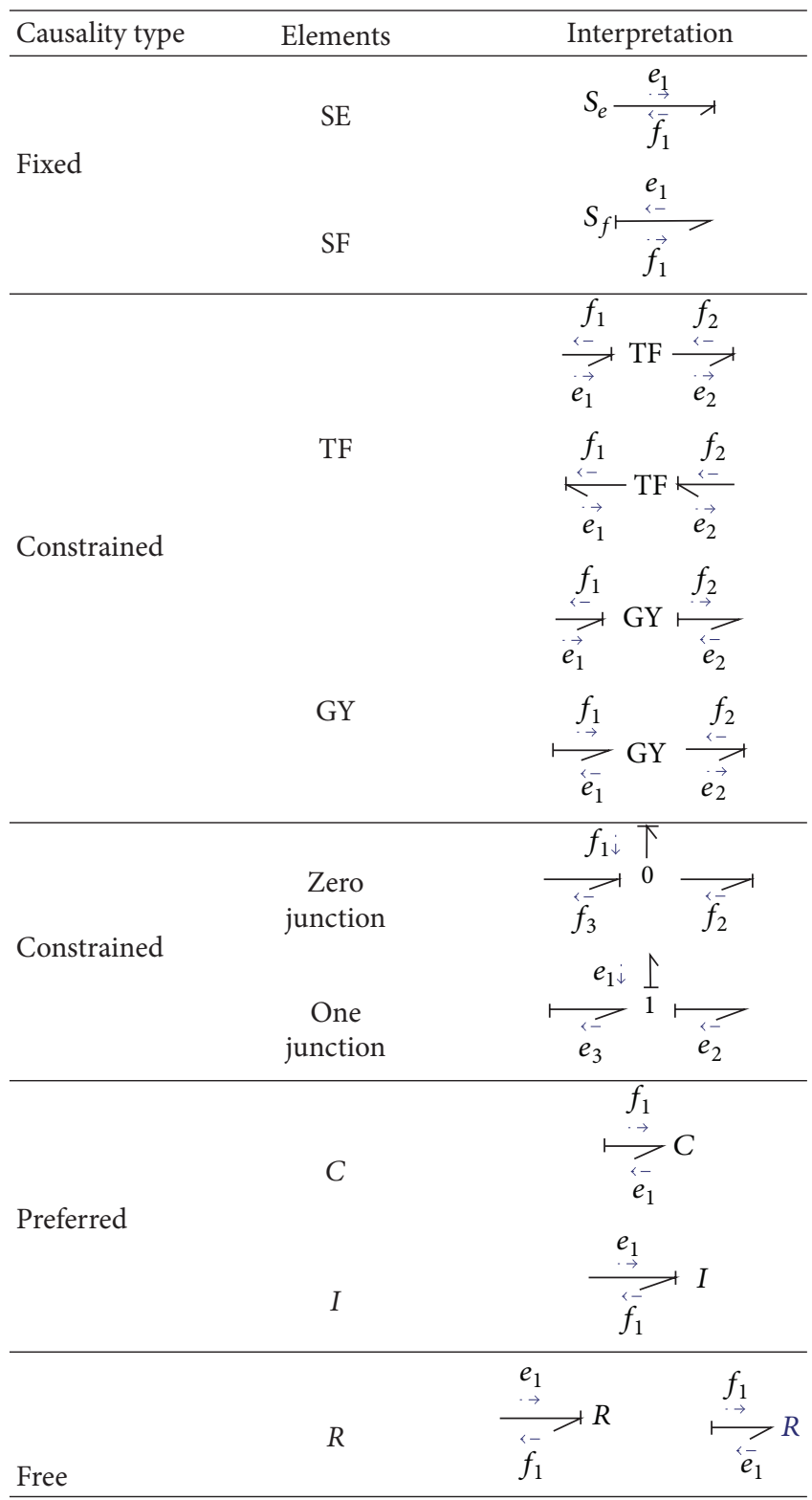

regeneration pump, hydropneumatic accumulator, proportional control valve, and other hydraulic components as shown in Figure 3 is modeled in power bond graph system model as seen in Figure 5. The details of the modeling in power bond graph approach are available in [31]. Modulated source of flow (MSf) represents the prime mover, where the flow output from the pump can be varied according to the input speed signal from the controller. Rest of the system determines the effort into the modulated source of flow. One junction number 1 (1-Jn-1) shows the torque loss due to mechanical friction at the input shaft of master hydraulic pump. The transformer TF: $D_{\mathrm{MP}}$ stands for volumetric displacement of master hydraulic pump, which converts the effort and flow in mechanical rotational domain to a hydraulics domain. Flow losses due to leakage and 


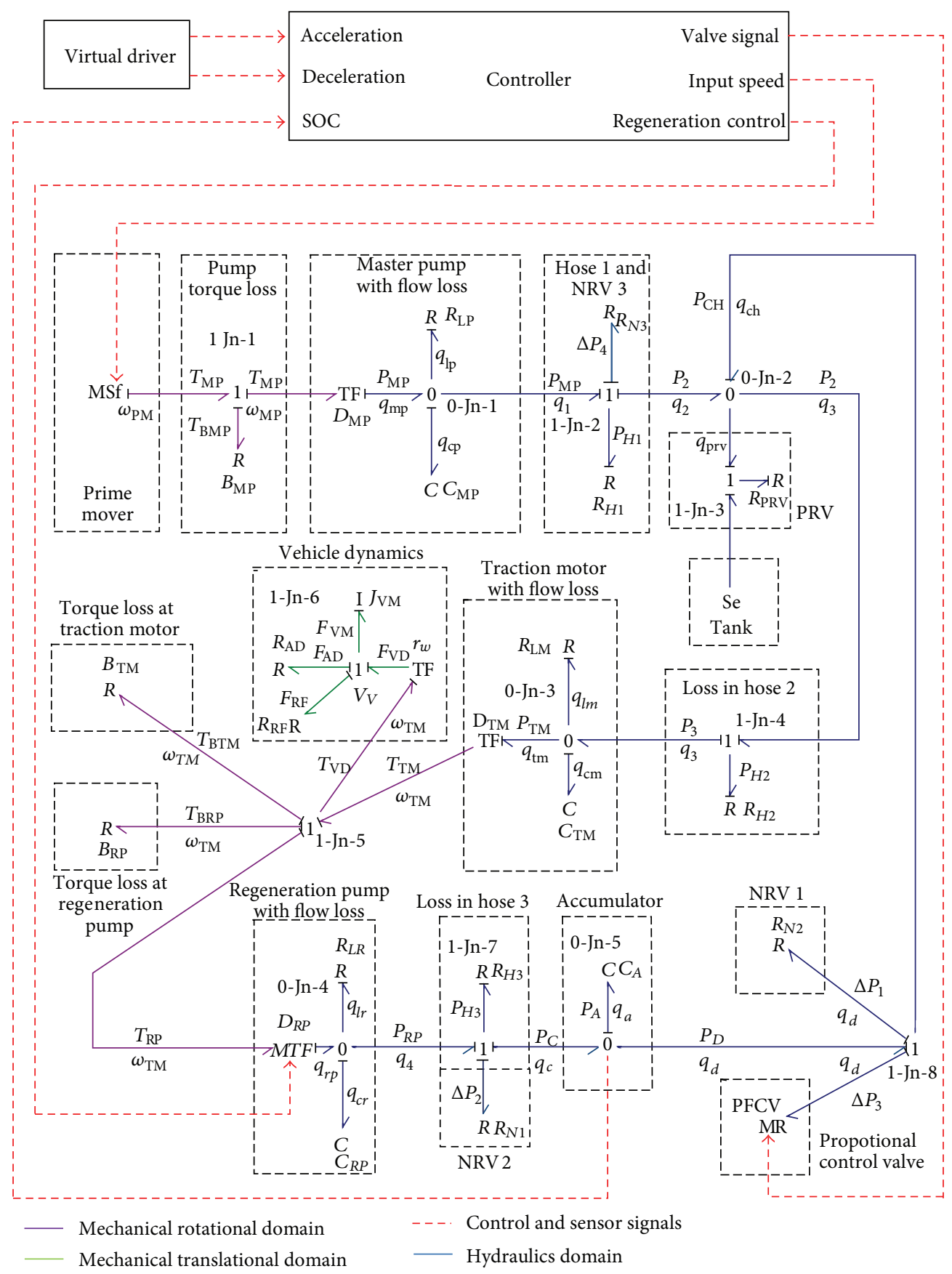

FIGURE 5: Power bond graph model of series hydraulic hybrid system.

compressibility of hydraulic oil in the master hydraulic pump are considered at $0-\mathrm{Jn}-1$.

The master hydraulic pump delivers the energy to the traction hydraulic motor through losses such as pressure loss at 1-Jn-2 and 1-Jn-4, which corresponds to pressure drop across hydraulic hoses 1 and 2, respectively. After considering the flow losses due to leakage and compressibility of hydraulic oil at traction hydraulic motor, the actual flow rate $\left(q_{\mathrm{tm}}\right)$ powers the traction hydraulic motor. Vehicle dynamics resistance and frictional resistances determine the torque at the traction hydraulic motor. The transformer TF: $R_{w}$, which represents the radius of the wheel, transforms the rotational domain parameters into translational domain. The longitudinal vehicle dynamics resistance such as rolling resistance, aerodynamic resistance, and vehicle inertia are considered at 1-Jn-6. Torque losses at traction motor and regeneration pump are added into the model at 1-Jn-5 to obtain the actual torque at respective shafts.

The displacement of the regeneration pump $\left(D_{\mathrm{RP}}\right)$ is represented as modulated transformer (MTF) in the model, 
which converts the mechanical rotation into hydraulic energy and modulation represents the possibility of the variation of the displacement factor of the regeneration pump. Hydraulic regenerative braking is carried out by varying the displacement factor of the regeneration pump, which loads the wheel and regenerates the useless kinetic energy into hydraulic energy during braking. At 0 -Jn-4, the flow from the regeneration pump is reduced due to flow losses such as leakage and loss due to compliance effect of oil $(C)$. The NRV 2 element that was considered at 1-Jn-7 allows flow rate $q_{4}$ to the hydropneumatic accumulator represented by compliance element $\left(C_{A}\right)$. The modulated resistance (MR) stands for proportional control valve, which discharges the stored regenerated energy in the hydropneumatic accumulator to the traction hydraulic motor via NRV 1 resistive element $\left(R_{N 1}\right)$.

Generally, all mechanical rotational subsystems such as prime mover, master hydraulic pump, traction hydraulic motor, and regeneration pump are kinetic energy parts in the system. However, the main kinetic energy part of the system is the hydraulic regenerative braking subsystem, which includes the traction hydraulic motor, regeneration hydraulic pump, and the vehicle. The useless kinetic energy in the traction hydraulic motor during braking phase is absorbed by the regeneration hydraulic pump and stored in the potential energy element hydropneumatic accumulator as potential energy by compressing the nitrogen gas. Hydraulic tank, which stores the hydraulic energy, is considered a potential energy element.

The following is a summary of the assumptions that were made, when developing the bond graph dynamic model of a SHHS.

(1) The prime mover dynamics is considered as ideal condition and without any losses in the prime mover.

(2) The reservoir (tank) pressure is at atmospheric pressure. As only gauge pressures are considered.

(3) Gas compression and expansion in the hydropneumatic accumulator is assumed to be obeying isentropic law.

(4) The proportional control valve dynamics is assumed to be based on orifice theory.

(5) The leakage flow through the cross-ports in the pump are laminar.

(6) Possible dynamical behavior of the pressure in the transmission lines between regeneration pump, accumulator, and proportional control valve is assumed to be negligible.

(7) Ineffective volumes, that is, the volume of the fluid in the hoses between the master hydraulic pump and the hydraulic motor, are neglected.

(8) The hydraulic pump and motor are assumed to be rigid, that is, no compliance in the walls. The stiffness of the hydraulic pump or motor walls is five times higher than that of the hydraulic oil. Therefore, when operating the system, compliance effect from pump or motor walls is negligible compared to the oil compliance.
(9) The inertial effect in all the hydraulic components and fluids are neglected.

The various hardware components used in the model are indicated in detail and mathematical model of each subsystem derived from junctions of bond graph model is explained in the followings sections.

3.3. Modeling Information of Subsystems. The subsystems considered in modeling a SHHS are prime mover, master hydraulic pump, pressure loss in hydraulic hose 1, pressure relief valve, pressure loss in hose 2 , traction hydraulic motor, vehicle dynamics, regeneration hydraulic pump, pressure loss in hydraulic hose 3, nonreturn valve, hydropneumatic accumulator, and proportional control valve. The dynamics of the each subsystem is explained as below.

(a) Prime Mover (PM). The prime mover of SHHS model represents an ideal rotary actuator. The actuator is mounted to the fixed world and applies an angular velocity. This angular velocity can be set to a (variable) value given by the input signal omega; the torque is determined by the rest of the system.

(b) Master Hydraulic Pump (MP). The master hydraulic pump is considered as a fixed displacement axial piston pump and is represented as transformer (TF) element named MP. Torque loss at the input shaft of master hydraulic pump is represented as pump mechanical efficiency friction coefficient $\left(B_{\mathrm{MP}}\right)$. The effort loss at 1-Jn-1 is implemented using a resistance element with the above said friction coefficient. At 1-Jn-1, the following equation shows the torque at the prime mover shaft:

$$
T_{\mathrm{PM}}=B_{\mathrm{MP}} \omega_{\mathrm{MP}}+T_{\mathrm{MP}} .
$$

The following equation gives the speed of the master hydraulic pump shaft or prime mover at 1-Jn-1:

$$
\omega_{\mathrm{PM}}=\omega_{\mathrm{MP}}=\frac{q_{\mathrm{mp}}}{D_{\mathrm{MP}}} .
$$

After torque loss, the following equation gives the torque at master hydraulic pump shaft:

$$
T_{\mathrm{MP}}=T_{\mathrm{PM}}-B_{\mathrm{MP}} \frac{q_{\mathrm{mp}}}{D_{\mathrm{MP}}} .
$$

The ideal transformer TF-element (MP) converts the effort $\left(T_{\mathrm{MP}}\right)$ and flow $\left(\omega_{\mathrm{MP}}\right)$ in rotational mechanical domain into effort $\left(P_{\mathrm{MP}}\right)$ and flow $\left(q_{\mathrm{mp}}\right)$ in the hydraulic domain. The hydraulic flow losses due to various leakages such as internal, external, and cross-port leakages are considered as a single resistive element $R_{\mathrm{LP}}$ at 0 -Jn-1. The flow loss due to compressibility or effect of bulk modulus of hydraulic oil is considered at this junction and is represented as compliance element $\left(C_{\mathrm{MP}}\right)$ and the compressibility of hydraulic oil is denoted as $C_{\mathrm{MP}}$. The element $C_{\mathrm{MP}}$ is assigned an integral causality and it represents the state variable ( $V_{i}$-instantaneous volume) at this junction. 
The hydraulic flow rate $\left(q_{1}\right)$ is equivalent to ideal hydraulic flow rate $\left(q_{\mathrm{mp}}\right)$ minus leakage flow loss $\left(q_{\mathrm{lp}}\right)$ and flow loss due to compressibility of oil $\left(q_{\mathrm{cp}}\right)$ is shown as

$$
q_{1}=q_{\mathrm{mp}}-q_{\mathrm{lp}}-q_{\mathrm{cp}}
$$

The following shows the hydraulic flow rate from the master hydraulic pump in terms of the state variable and resistance elements:

$$
q_{1}=q_{2}=D_{\mathrm{MP}} \omega_{\mathrm{MP}}-\frac{P_{\mathrm{MP}}}{R_{\mathrm{LP}}}-\frac{V_{01}}{B} \frac{d P_{\mathrm{MP}}}{d t} .
$$

The parameter $R_{\mathrm{LP}}$ is the leakage resistance of the pump obtained by measuring the amount of bypass fluid from the case drain port for three different speeds of the pump over a period of time and with constant working temperature [32].

Pressure at the output port of master hydraulic pump is given as

$$
P_{\mathrm{MP}}=\frac{T_{\mathrm{MP}}}{D_{\mathrm{MP}}}
$$

(c) Pressure Loss in Hydraulic Hose 1. The pressure drop across the hose between master hydraulic pump and fourway junction, which connects pressure relief valve (PRV) and proportional control valve, is considered in this dynamic system model. In 1-Jn-2, the resistance $R_{H 1}$ is provided to the effort $\left(P_{\mathrm{MP}}\right)$, which creates a pressure drop across the hydraulic hose. The pressure $\left(P_{\mathrm{MP}}\right)$ at the master hydraulic pump is shown as

$$
P_{\mathrm{MP}}=P_{H 1}+P_{2}+\Delta P_{4}
$$

The following equation shows the pressure $P_{2}$ at the four-way junction end of hose:

$$
P_{2}=P_{\mathrm{MP}}-R_{H 1} q_{2}-\Delta P_{4}
$$

(d) Pressure Relief Valve. The effect of pressure relief valve is reflected at $0-\mathrm{Jn}-2$. The flow rate to the traction hydraulic motor is determined by flow rates across the PRV and proportional control valve through nonreturn valve (NRV) 1 . At 0 -Jn-2, effort remains constant and the following equation gives the flow rate $\left(q_{3}\right)$ to the traction hydraulic motor:

$$
q_{3}=q_{2}-q_{\mathrm{prv}}-q_{\mathrm{ch}}
$$

The following shows the flow rate through the PRV:

$$
q_{\text {prv }}=\left(\Delta P_{5}-P_{\text {set }}\right) G_{0}+G_{\text {prv }} \Delta P_{5} .
$$

Substituting (10) in (9) gives the flow variable $\left(q_{3}\right)$ in terms of NRV 1 and PRV dynamics shown as

$$
q_{3}=q_{2}-\left[\left(\Delta P_{5}-P_{\text {set }}\right) G_{0}+G_{\mathrm{prv}} \Delta P_{5}\right]-q_{\mathrm{ch}} .
$$

(e) Pressure Loss at Hydraulic Hose 2. The pressure drop across the hose between 0 -Jn-2 and traction hydraulic motor is considered in this dynamic system model. At 1-Jn-4, the resistance $R_{H 2}$ is provided to the effort $\left(P_{2}\right)$, which creates a pressure drop across the hydraulic hose. At 1-Jn-4, flow remains constant and the junction equation is shown as follows:

$$
P_{2}=P_{H 2}+P_{3}
$$

The pressure $\left(P_{3}\right)$ at the traction hydraulic motor end of hydraulic hose is shown as follows:

$$
P_{3}=P_{\mathrm{TM}}=P_{2}-R_{H_{2}} q_{3} .
$$

(f) Traction Hydraulic Motor (TM). The traction hydraulic motor is considered as a fixed displacement axial piston pump and it is represented as transformer (TF) element. The hydraulic flow rate $\left(q_{\mathrm{tm}}\right)$ at the traction hydraulic motor is equivalent to cumulative hydraulic flow rate $\left(q_{3}\right)$ from master hydraulic pump and hydropneumatic accumulator minus leakage flow loss and flow loss due to compressibility of oil at traction hydraulic motor is shown as follows:

$$
q_{\mathrm{tm}}=q_{3}-q_{\mathrm{lm}}-q_{\mathrm{cm}}
$$

The following equation shows the hydraulic flow rate to the traction hydraulic motor in terms of the state variable (volume of oil and pressure drop) and resistance elements (leakage resistance):

$$
\begin{aligned}
q_{\mathrm{tm}}= & q_{2}-q_{\mathrm{ch}}-\left(\Delta P_{5}-P_{\mathrm{set}}\right) G_{0} \\
& -G_{\mathrm{PRV}} \Delta P_{5}-\frac{P_{3}}{R_{\mathrm{LM}}}-\frac{V_{02}}{B} \frac{d P_{3}}{d t} .
\end{aligned}
$$

The following equation gives the pressure at the traction hydraulic motor:

$$
P_{\mathrm{TM}}=\frac{T_{\mathrm{TM}}}{D_{\mathrm{TM}}} .
$$

The ideal transformer TF-element converts the effort $\left(P_{\mathrm{TM}}\right)$ and flow $\left(q_{\mathrm{mp}}\right)$ in the hydraulic domain into effort $\left(T_{\mathrm{TM}}\right)$ and flow $\left(\omega_{\mathrm{TM}}\right)$ in the rotational mechanical domain. Torque loss at the output shaft of traction hydraulic motor is represented as motor mechanical efficiency friction coefficient $\left(B_{\mathrm{TM}}\right)$ at 1-Jn-5.

(g) Vehicle Dynamics. It consists of torque due to vehicle mass, aerodynamic force, and rolling resistance force. Characteristics of the vehicle (Honda Brio) are discussed below.

The following equation shows the radius of the wheel, $r_{w}$ from the tire dimensions:

$$
r_{w}=0.5 \times d_{\text {rim }}+0.01 \times H \times w .
$$

The total vehicle mass, $m_{\text {veh }}$ accounting for wheel inertia effect in linear motion is shown as follows:

$$
m_{\mathrm{veh}}=m+4 \times \frac{J_{w}}{r_{w}^{2}} .
$$


The inertial resistance force, $F_{\mathrm{VM}}$ is obtained through the following:

$$
F_{\mathrm{VM}}=m_{\mathrm{veh}} g \sin [\arctan (0.01 \times \alpha)] .
$$

Road configuration, the resistance force due to aerodynamic drag, $F_{\mathrm{AD}}$ is calculated as follows:

$$
F_{\mathrm{AD}}=0.5 \rho_{\mathrm{air}} C_{x} a_{s}\left(V_{v}+V_{\text {wind }}\right)^{2} .
$$

The following equation gives the rolling friction resistance force, $F_{\mathrm{RF}}$ as shown below:

$$
F_{\mathrm{RF}}=m_{\mathrm{veh}} g\left(f+k V_{v}\right) .
$$

At 1-Jn-6, the force due to vehicle dynamics is shown as follows:

$$
F_{\mathrm{VD}}=F_{\mathrm{VM}}+F_{\mathrm{RF}}+F_{\mathrm{AD}} .
$$

The ideal transformer TF-element $\left(r_{w}\right)$ converts effort $\left(F_{\mathrm{VD}}\right)$ and flow $\left(V_{v}\right)$ in the mechanical translation domain into the effort $\left(T_{\mathrm{VD}}\right)$ and flow $\left(\omega_{\mathrm{TM}}\right)$ in the mechanical rotation domain. At 1-Jn-5, flow remains unchanged; (23) shows the torque at the traction motor:

$$
T_{\mathrm{TM}}=T_{\mathrm{RP}}+T_{\mathrm{VD}}+T_{\mathrm{BTM}}+T_{\mathrm{BRP}} .
$$

The following equation gives the torque at the traction motor in terms of vehicle characteristics:

$$
T_{\mathrm{TM}}=T_{\mathrm{RP}}+r_{w}\left(F_{\mathrm{VM}}+F_{\mathrm{RF}}+F_{\mathrm{AD}}\right)+B_{\mathrm{TM}} \omega_{\mathrm{TM}}+B_{\mathrm{RP}} \omega_{\mathrm{TM}} .
$$

(h) Regeneration Pump (RP). It is considered as a variable displacement axial piston pump and it is represented as modulated transformer (MTF) element. Torque loss at the input shaft of master hydraulic pump is represented as regeneration pump mechanical efficiency friction coefficient $\left(B_{\mathrm{RP}}\right)$. The effort loss at 1-Jn-5 is implemented and the following equation shows the torque at regeneration pump:

$$
T_{\mathrm{RP}}=T_{\mathrm{TM}}-r_{w}\left(F_{\mathrm{VM}}+F_{\mathrm{RF}}+F_{\mathrm{AD}}\right)-B_{\mathrm{TM}} \omega_{\mathrm{TM}}-B_{\mathrm{RP}} \omega_{\mathrm{TM}} .
$$

The following equation gives speed of the regeneration pump shaft or prime mover at 1-Jn-5:

$$
\omega_{\mathrm{RP}}=\omega_{\mathrm{TM}}=\frac{q_{\mathrm{rp}}}{D_{\mathrm{RP}}} .
$$

The ideal modulated transformer MTF-element converts the effort $\left(T_{\mathrm{TM}}\right)$ and flow $\left(\omega_{\mathrm{TM}}\right)$ in the rotational mechanical domain into effort $\left(P_{\mathrm{RP}}\right)$ and flow $\left(q_{\mathrm{rp}}\right)$ in the hydraulic domain. The hydraulic flow losses due to various leakages such as internal, external, and cross-port leakages are considered as a single resistive element $R_{\mathrm{RP}}$ at 0 -Jn-4. The flow loss due to compressibility of hydraulic oil is considered and is represented as compliance element. The compressibility of hydraulic oil is denoted as $C_{\mathrm{RP}}$.
The hydraulic flow rate $\left(q_{4}\right)$, after flow loss, is equivalent to ideal hydraulic flow rate $\left(q_{\mathrm{rp}}\right)$ minus leakage flow loss $\left(q_{\mathrm{lr}}\right)$ and flow loss $\left(q_{\mathrm{cr}}\right)$ due to compressibility of oil is shown as follows:

$$
q_{4}=q_{c}=q_{\mathrm{rp}}-q_{\mathrm{lr}}-q_{\mathrm{cr}} .
$$

The following equation shows the hydraulic flow rate from the regeneration pump in terms of the state variable and resistance elements:

$$
q_{4}=q_{c}=D_{\mathrm{RP}} \omega_{\mathrm{tm}}-\frac{P_{\mathrm{RP}}}{R_{\mathrm{LR}}}-\frac{B}{V_{03}} \frac{d P_{\mathrm{RP}}}{d t} .
$$

Pressure at the output port of regeneration pump is shown as follows:

$$
\begin{gathered}
P_{\mathrm{RP}}=\frac{1}{D_{\mathrm{RP}}}\left(T_{\mathrm{TM}}-r_{w}\left(F_{\mathrm{VM}}+F_{\mathrm{RF}}+F_{\mathrm{AD}}\right)\right. \\
\left.-B_{\mathrm{TM}} \omega_{\mathrm{TM}}-B_{\mathrm{RP}} \omega_{\mathrm{TM}}\right) .
\end{gathered}
$$

(i) Pressure Loss in Hydraulic Hose 3. The pressure drop across the hose between regeneration pump and NRV 2 is considered in this model. In 1-Jn-6, flow remains unchanged and the resistance $R_{H 3}$ is provided to the effort $\left(P_{\mathrm{RP}}\right)$, which creates a pressure drop across the hydraulic hose. The following equation shows the pressure $P_{4}$ at the NRV 2 end of hydraulic hose 3 :

$$
P_{\mathrm{C}}=P_{R P}-q_{4} R_{H 3}-q_{4} R_{N 1} .
$$

(j) NRV. This valve allows unidirectional flow towards the hydraulic accumulator from regeneration pump. During acceleration of the vehicle, NRV 2 restricts flow through regeneration pump. The following equation shows the pressure at nonreturn end of NRV 2 and flow rate remains the same across the NRV 2:

$$
\Delta P_{2}=P_{\mathrm{RP}}-P_{c}-q_{4} R_{H 3} .
$$

(k) Hydropneumatic Accumulator. The inert gas (nitrogen gas) is compressed and expanded under isentropic conditions. Pressure of the fluid in the accumulator is computed by the use of an algebraic equation derived from the isentropic law, $P V^{\gamma}=$ constant. Input of the subsystem is the flow to the accumulator, $q_{a}$. At any time, the pressure of gas is equal to the pressure of the fluid in the accumulator and it is represented as $P_{\text {gas }}=P_{A}$. The total volume $\left(V_{a}\right)$ of accumulator is equal to the sum of the volume of gas $\left(V_{\text {gas }}\right)$ and the volume of fluid $\left(V_{\text {oil }}\right)$ and is constant at any time as shown as follows:

$$
\frac{d V_{a}}{d t}=\frac{d V_{\mathrm{gas}}}{d t}+\frac{d V_{\mathrm{oil}}}{d t}=0 .
$$

On the other hand, the variation of fluid volume is equal to the input flow $\left(q_{a}\right)$ as written as

$$
\frac{d V_{\text {oil }}}{d t}=q_{a} .
$$


The following equation shows the gas volume variation:

$$
\frac{d V_{\mathrm{gas}}}{d t}=-q_{a}
$$

Let us consider nominal volume $\left(V_{0 \text { gas }}\right)$ and precharge pressure $\left(P_{0 \text { gas }}\right)$, from isentropic law $(\gamma=1.4)$ is shown as follows:

$$
P_{\text {gas }}\left(V_{\text {gas }}\right)^{\gamma}=P_{\text {0gas }}\left(V_{\text {ogas }}\right)^{\gamma}=\text { const. }
$$

Finally, the pressure in the accumulator is shown as follows:

$$
P_{\text {gas }}=\frac{P_{0 \text { gas }}\left(V_{0 \text { gas }}\right)^{\gamma}}{\int q_{a} d t} .
$$

(l) Proportional Flow Control Valve (PFCV). The regenerated energy stored during the braking is discharged to traction motor using the proportional control valve at subsequent acceleration of the vehicle. At proportional control valve, the following equation shows the discharge flow rate from the proportional control valve at 1-Jn-8:

$$
q_{d}=C_{d} A \sqrt{\frac{2 \Delta P_{3}}{\rho}}+G_{\mathrm{LP}} \cdot \Delta P_{3} .
$$

The following equation shows the pressure difference across the proportional control valve:

$$
\Delta P_{3}=P_{\mathrm{CH}}-P_{D} .
$$

\section{Parametric Study}

Figure 6 shows the typical federal urban driving cycle [20] used as an input for the series hydraulic hybrid system model. It represents the velocity of the vehicle versus time and it consists of several acceleration and braking phases between 0 second and 600 seconds of driving cycle time. The focus of present simulation study starts from 134th second to 492th second for one acceleration and deceleration cycle. The dynamic characteristics of series hydraulic hybrid system in a vehicle are studied and analyzed through simulation. Input system parameters used for simulation in power bond graph model are shown in Table 3. These parameters are chosen from the published literatures. The system simulation and design optimization of series hydraulic hybrid system considers a commercially available $65 \mathrm{~kW}$ Honda car. It is defined in the vehicle dynamic subsystem model before starting the system simulation and design optimization. The specifications selected from the Honda car as input parameters to the model are listed in Table 3. The system behavior is analyzed as below from 134th second onwards.

Figure 7 shows the variation of various parameters of interest with respect to driving cycle time for 2 cycles of the federal urban driving cycle. Several points of interest and corresponding parameters values are indicated. The points of interest on the driving cycle are start of acceleration (134s), end of acceleration (164s), start of braking (460 s), and end

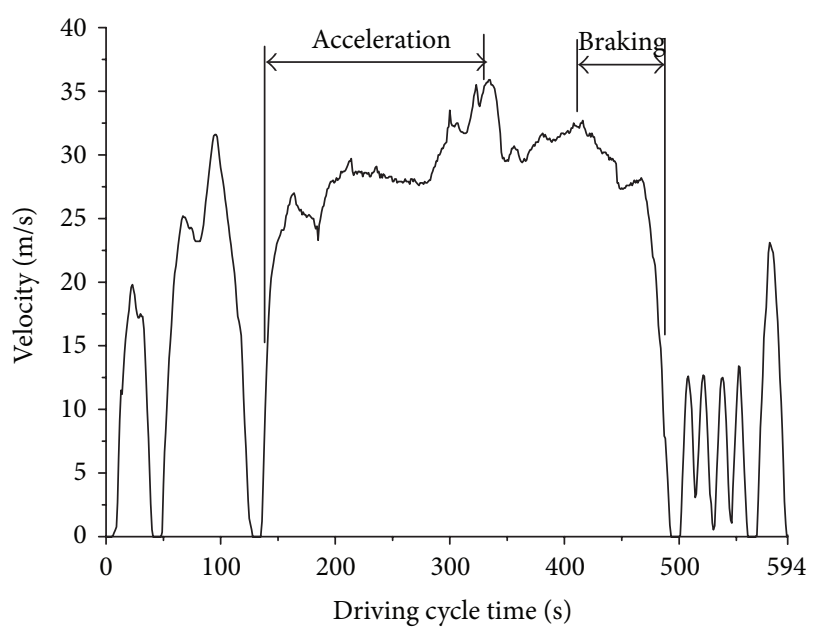

Figure 6: Federal urban driving cycle [20].

of braking (492s). Figure 7(a) shows the input speed to the master hydraulic pump. During acceleration of vehicle, prime mover as well as hydropneumatic accumulator simultaneously powers the hydraulic traction motor. The angular speed of the pump increases from 0 to $134 \mathrm{rad} / \mathrm{s}$ at 164th of driving cycle time, thus delivering the hydraulic energy to the hydraulic traction motor. The vehicle starts accelerating from 134 th second to 165 th second in the driving cycle.

The hydraulic traction motor is powered by the hydraulic energy from the master hydraulic pump and the hydraulic accumulator to meet the power demand at the wheels. The change in flow rate of hydraulic oil from the accumulator between 134th and 165th second as seen in Figure 7(b) shows the discharge of hydraulic energy from the hydropneumatic accumulator. Here, negative sign of the volumetric flow rate indicates the discharge of oil from the accumulator and positive sign indicates the charging of oil into the accumulator.

The hydraulic oil volume in the hydraulic accumulator decreases from the initial stored value of $6.3 \times 10^{-3} \mathrm{~m}^{3}$ to $1.7 \times 10^{-3} \mathrm{~m}^{3}$ as shown in Figure $7(\mathrm{c})$. The corresponding change in accumulator oil pressure is from $22 \mathrm{MPa}$ to $12 \mathrm{MPa}$ as shown in Figure 7(d). It is also observed from Figure 7(e) that hydraulic traction motor speed increases from 0 to $192 \mathrm{rad} / \mathrm{s}$ at 165th second of driving cycle time due to the combined power from the two sources. The variables in the system parameters indicate that the prime mover as well as hydropneumatic accumulator simultaneously deliver the power to the hydraulic traction motor in the acceleration mode of the system.

In cruising or constant velocity drive of vehicle, hydraulic power from the hydropneumatic accumulator is suspended and only prime mover supplies power to drive the hydraulic traction motor; that is, input speed remains steady from 166th second to 459th second in cycle time as shown in Figure 7(a). At the same time, hydropneumatic accumulator gets charged and discharged with respect to the acceleration and braking. The flow rate from hydropneumatic accumulator after the end of acceleration (164 s) until start of the braking (460 s) in total driving cycle time substantiates the charging and discharging of the accumulator as shown in Figure 7(b). Hydropneumatic 
TABLE 3: Input parameters to power bond graph model.

\begin{tabular}{lcl}
\hline Parameters & Quantity & Description \\
\hline$B_{\mathrm{MP}}(\mathrm{Nms})$ & $1.65 \times 10^{-1}$ & $\begin{array}{l}\text { Master pump mechanical efficiency friction coefficient } \\
\text { Regeneration pump mechanical efficiency friction } \\
\text { coefficient }\end{array}$ \\
$B_{\mathrm{RP}}(\mathrm{Nms})$ & $1.65 \times 10^{-1}$ & $\begin{array}{l}\text { Traction motor mechanical efficiency friction } \\
\text { coefficient }\end{array}$ \\
$B_{\mathrm{TM}}(\mathrm{Nms})$ & $1.65 \times 10^{-1}$ & Volumetric displacement of master pump \\
$D_{\mathrm{MP}}\left(\mathrm{m}^{3} / \mathrm{rev}\right)$ & $1.1 \times 10^{-5}$ & Master pump internal leakage resistance \\
$R_{\mathrm{LP}}\left(\mathrm{Pa}-\mathrm{s} / \mathrm{m}^{3}\right)$ & $1 \times 10^{3}$ & Nominal volume of accumulator \\
$V_{a}\left(\mathrm{~m}^{3}\right)$ & 0.015 & Precharge pressure of accumulator \\
$P_{0 \mathrm{gas}}(\mathrm{Pa})$ & $9 \times 10^{6}$ & Maximum operating pressure \\
$P_{\mathrm{prv}}(\mathrm{Pa})$ & $40 \times 10^{6}$ & Volumetric displacement of traction motor \\
$D_{\mathrm{TM}}\left(\mathrm{m}^{3} / \mathrm{rev}\right)$ & $8.3 \times 10^{-6}$ & Volumetric displacement of hydraulic regeneration \\
$D_{\mathrm{RP}}\left(\mathrm{m}^{3} / \mathrm{rev}\right)$ & $1.5 \times 10^{-5}$ & pump \\
$F_{\mathrm{VH}}(\mathrm{N})$ & 9500 & Resistant force due to vehicle moment of inertia \\
$F_{\mathrm{RF}}(\mathrm{N})$ & 8.45 & Vehicle rolling resistance force \\
$r_{W}(\mathrm{~m})$ & 0.175 & Radius of the wheel \\
$a_{s}\left(\mathrm{~m}^{2}\right)$ & 0.5 & Front area of the vehicle
\end{tabular}

accumulator volume and oil pressure remains steady during the cruising mode as shown in Figure 7(c) and Figure 7(d) from 166 to 459 th second in cycle time.

In the braking phase of the vehicle between 460th and 492th second of the driving cycle time, the volumetric flow of oil to the accumulator takes place as shown in Figure 7(b). In addition, the hydropneumatic accumulator volume expands adiabatically from $1.4 \times 10^{-3} \mathrm{~m}^{3}$ to $6.4 \times 10^{-3} \mathrm{~m}^{3}$ as shown in Figure $7(\mathrm{c})$ and volumetric flow rate from hydraulic regeneration pump increases to a maximum of $2.1 \times 10^{-4} \mathrm{~m}^{3} / \mathrm{s}$ and then gradually reduces to zero flow rate as shown in Figure $7(\mathrm{~g})$. At the same time, pressure also rises from $12 \mathrm{MPa}$ to $22 \mathrm{MPa}$ as shown in Figure $7(\mathrm{~d})$. It is observed that from the above response that $5 \times 10^{-3} \mathrm{~m}^{3}$ of hydraulic oil volume is stored in the accumulator. The input speed to the pump decreases from 141 to $0 \mathrm{rad} / \mathrm{s}$ as shown in Figure 7(a) and correspondingly system output speed; that is, speed of the traction motor decreases from 192 to $0 \mathrm{rad} / \mathrm{s}$ as shown in Figure 7(e).

The instantaneous output power of the system as shown in Figure 7(f) substantiates the variation in the power variables. The useless kinetic energy available during braking is recovered using hydraulic regeneration, which can be seen from the response curves in Figure 7(g) and Figure 7(e). Moreover, hydraulic regenerative braking helps in improving the energy efficiency and fuel economy and reduces mechanical brake wear and reduces emissions from the engine.

The system input power and the corresponding output power variations with respect to driving cycle time for one cycle are shown in Figure 8(a) and Figure 8(b), respectively. These are used to evaluate the energy consumed and energy delivered by the system. Moreover, energy recovered during braking is evaluated from the instantaneous hydraulic regeneration power as shown in Figure 8(c). To understand the system energy efficiency trends, the energy values for one driving cycle are calculated by the areas under the curve in Figure 8. Input energy consumed and output energy delivered by the system for the given federal urban driving cycle are $9389 \mathrm{~kJ}$ and $8646 \mathrm{~kJ}$, respectively, as shown in Figure 9. The energy efficiency of the system $\left(\eta_{\mathrm{EE}}\right)$ is evaluated as $92 \%$ from ratio of the input energy consumed and output energy delivered by the system. The hydraulic regeneration efficiency $\left(\eta_{\mathrm{RE}}\right)$ of $16.4 \%$ is achieved, which is the ratio of energy recovered or regenerated energy $\left(R_{E}\right)-213 \mathrm{~kJ}$ from available braking energy $\left(B_{E}\right)$ of $1300 \mathrm{~kJ}$ as shown in Figure 9.

\section{Design Optimization}

5.1. Objective Function Formulation. Parametric design optimization is an essential procedure for designing the physical and process parameters of series hydraulic hybrid system for better performance and energy efficiency. Optimal system parameters values are determined by maximizing system energy efficiency using Broydon Fletcher Goldfarb Shanno (BFGS) optimization method [33]. This method not only uses the gradient of a function but also the second order gradient to determine the search direction. The second order gradient is estimated based on previous search directions. The search direction is kept for each new step until a minimum has been found. Then a new search direction is determined and the process continues.

From the junction equations and subsystem equations in the system model derived earlier, the input power $\left(P_{\mathrm{IN}}\right)$ to the system is derived as a function of system parameters as follows:

$$
\begin{aligned}
P_{\mathrm{IN}}= & \omega_{\mathrm{PM}} D_{\mathrm{MP}}\left(R_{H 1} q_{2}+P_{\mathrm{H} 2}+\frac{T_{\mathrm{TM}}}{D_{\mathrm{TM}}}+\Delta P_{4}\right) \\
& +\frac{\omega_{\mathrm{PM}} B_{\mathrm{MP}}}{D_{\mathrm{MP}}}\left(q_{\mathrm{tm}}+\frac{P_{3}}{R_{\mathrm{LM}}}+\frac{V_{02}}{B} \frac{d P_{3}}{d t}+\frac{V_{01}}{B} \frac{d P_{\mathrm{MP}}}{d t}\right.
\end{aligned}
$$




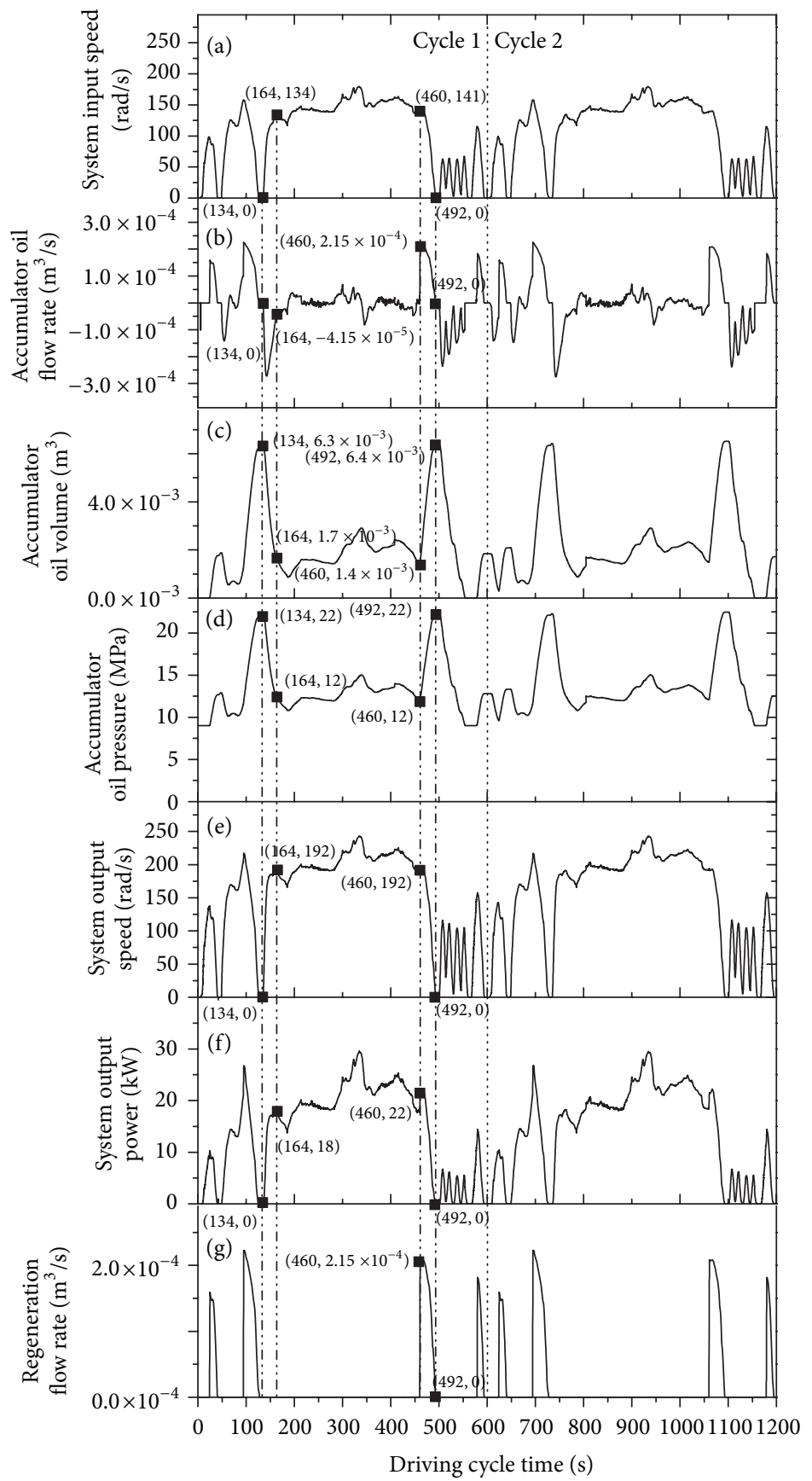

FIGURE 7: System parameters versus driving cycle time.

$$
\begin{aligned}
& +\left[\left(\Delta P_{5}-P_{\mathrm{set}}\right) G_{0}+G_{\mathrm{prv}} \Delta P_{5}\right]-q_{\mathrm{ch}} \\
& \left.+\frac{\left(R_{H 1} q_{2}+P_{H 2}+T_{\mathrm{TM}} / D_{\mathrm{TM}}+\Delta P_{4}\right)}{R_{\mathrm{LP}}}\right) .
\end{aligned}
$$

The following equation shows the output power $\left(P_{\text {OUT }}\right)$ delivered from the system as a function of system parameters:

$$
P_{\mathrm{OUT}}=\left(\frac{T_{\mathrm{MP}}}{D_{\mathrm{MP}}}-R_{H 1} q_{2}-\Delta P_{42}-R_{H 2} q_{3}\right)
$$

$$
\begin{aligned}
\times( & D_{\mathrm{MP}} \omega_{\mathrm{MP}}-\frac{T_{\mathrm{MP}}}{D_{\mathrm{MP}} R_{\mathrm{LP}}}-\frac{V_{01}}{B} \frac{d P_{\mathrm{MP}}}{d t} \\
& -\frac{V_{02}}{B} \frac{d P_{3}}{d t}-\frac{T_{\mathrm{TM}}}{D_{\mathrm{TM}} R_{\mathrm{LM}}}-P_{0 \text { gas }}\left(V_{0 \text { gas }}\right)^{\gamma} \frac{d P_{\text {gas }}}{d t} \\
& \left.-\left(\Delta P_{5}-P_{\text {set }}\right) G_{0}-G_{\mathrm{PRV}} \Delta P_{5}\right) .
\end{aligned}
$$

Detailed derivation of input power equation is available at the Appendix. Objective functions of the system are derived as shown below. 


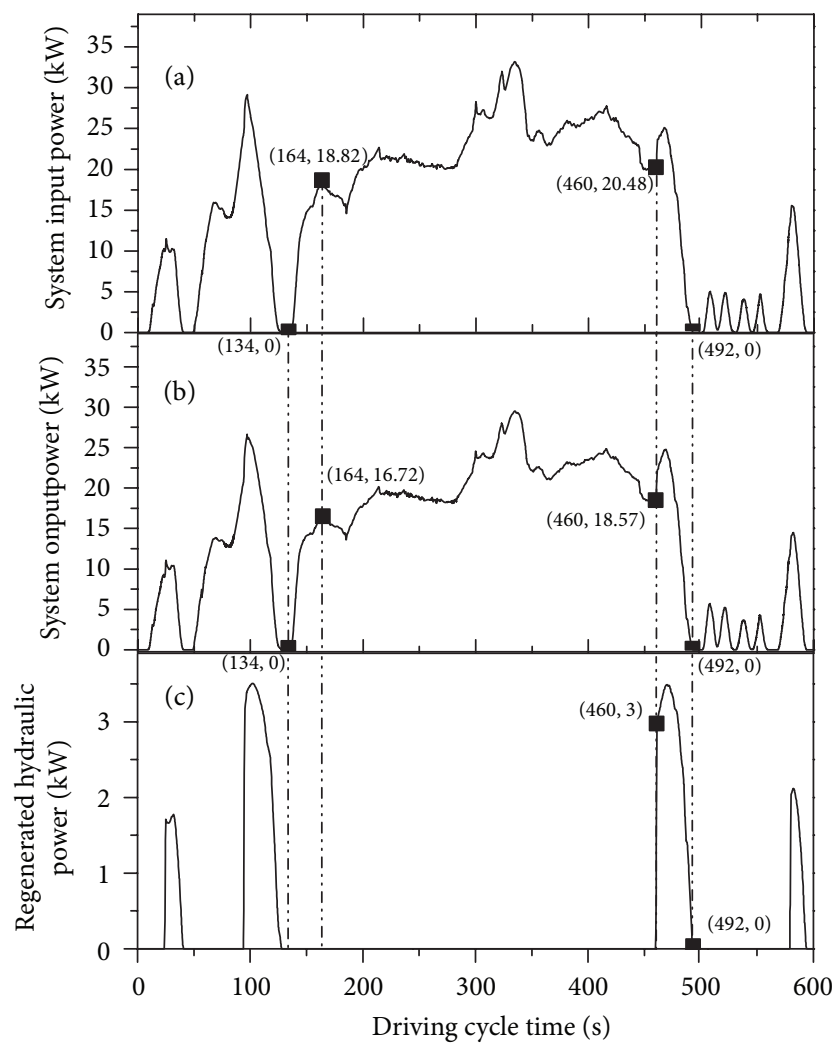

FIGURE 8: System input, output, and regeneration power plots.

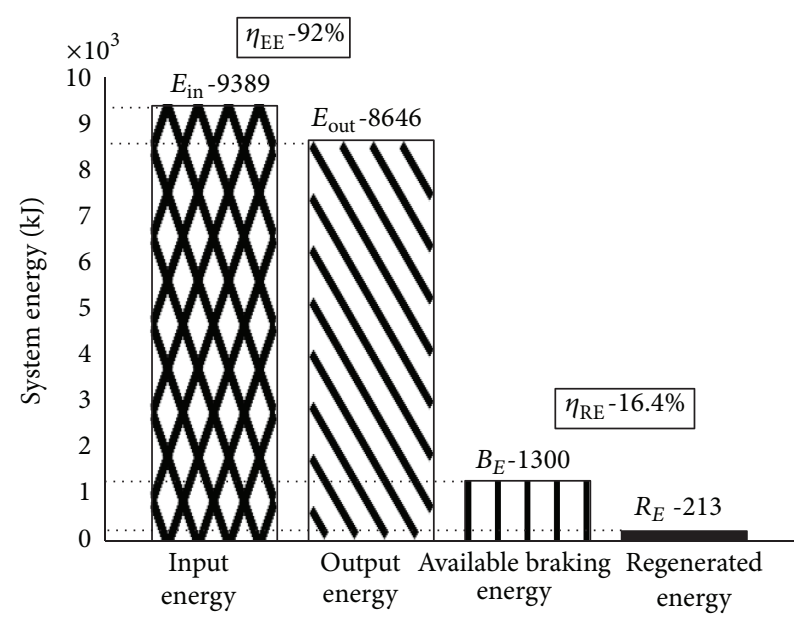

FIgURE 9: System efficiency study.

The following equation shows the system output energy $\left(E_{\mathrm{OUT}}\right)$ :

$$
E_{\mathrm{OUT}}=\int_{0}^{T} P_{\mathrm{OUT}} d t .
$$

The following equation shows the system input energy $\left(E_{\mathrm{IN}}\right)$ :

$$
E_{\mathrm{IN}}=\int_{0}^{T} P_{\mathrm{IN}} d t
$$

The two objective functions for the multiobjective optimization problems are maximize system output energy and minimize system input energy for the supplied input power.

The energy efficiency of the system, $\eta_{\mathrm{EE}}$, which is the ratio of system energy delivered to the system to the energy consumed, is formulated as shown in (43). The composite function-maximize energy efficiency is given as

$$
\eta_{\mathrm{EE}}=\left(\frac{E_{\mathrm{OUT}}}{E_{\mathrm{IN}}}\right) \times 100 .
$$

The system parameters are optimized with composite function-maximizing energy efficiency, which satisfies both the objective functions-maximize system output energy and minimize system input energy. However, the design optimization process and energy management control strategy will be responsible for maximizing the designated cost function in (43).

Mainly two constraints are imposed and they are as follows. (1) Accumulator size-energy density of hydropneumatic accumulator depends on its own size. However, oversized accumulator would increase vehicle weight and vehicle fuel consumption at the same time.

(2) Precharge pressure-power density of the hydropneumatic accumulator depends on precharge pressure. Usually, precharge is 0.9 times the minimum accumulator pressure. In this system, the lower the precharge pressure provides higher power density.

The system simulation is carried out for each set of input variables (design variables) to determine the output variables, that is, input, output energy, and energy efficiency of the system. Optimization results will be discussed in the following subsection.

5.2. Results and Discussion. The design optimization of series hydraulic hybrid system considers optimizing the key system parameters or design variables such as precharge pressure $\left(P_{\text {ogas }}\right)$, nominal volume of accumulator $\left(V_{a}\right)$, volumetric displacement of master hydraulic pump $\left(D_{\mathrm{MP}}\right)$, and traction hydraulic motor $\left(D_{\mathrm{TM}}\right)$ which has direct effect on the energy efficiency of the system. The parametric simulation study is used to identify the upper bound and lower bound values of these parameters. Table 4 tabulates the input parameters of design variables considered for the optimization. The design optimization process is a process in which the key system parameters or design variables are varied from lower bound limit to upper bound limit with a step size value and the detailed procedure for the optimization process is given in [31]. The different combination of these design variables values form a design ID or parameter set. The maximum system energy efficiency for the particular optimal parameter set or design ID is as shown in Figure 10. It is found that, after several iterations, the system energy efficiency reaches maximum of $95.6 \%$ and is found at 34 th iteration. During the optimization, the energy efficiency of the system increases from $91.8 \%$ to $95.6 \%$ and design ID 34 with maximum energy efficiency of $95.6 \%$ is chosen as a global optimal point.

Table 5 tabulates the corresponding design ID or parameter set for the 34 th iteration (global optimal point) 
TABLE 4: Input parameters to design optimization process.

\begin{tabular}{lccc}
\hline Design variables & Lower bound value & Upper bound value & Step size \\
\hline$V_{a}\left(\mathrm{~m}^{3}\right)$ & 0.008 & 0.02 & 0.001 \\
$D_{\mathrm{MP}}\left(\mathrm{m}^{3} / \mathrm{rev}\right)$ & $6 \times 10^{-6}$ & $1.4 \times 10^{-5}$ & $1 \times 10^{-6}$ \\
$D_{\mathrm{TM}}\left(\mathrm{m}^{3} / \mathrm{rev}\right)$ & $8 \times 10^{-6}$ & $6.8 \times 10^{-5}$ & $0.1 \times 10^{-6}$ \\
$P_{0 \mathrm{gas}}(\mathrm{Pa})$ & $6 \times 10^{6}$ & $1.5 \times 10^{7}$ & $1 \times 10^{6}$ \\
\hline
\end{tabular}

TABLE 5: Design optimization-optimal values.

\begin{tabular}{lcc}
\hline Design variables & Initial values & Optimal values \\
\hline$V_{a}\left(\mathrm{~m}^{3}\right)$ & 0.015 & 0.008 \\
$D_{\mathrm{MP}}\left(\mathrm{m}^{3} / \mathrm{rev}\right)$ & $1.1 \times 10^{-5}$ & $1.4 \times 10^{-5}$ \\
$D_{\mathrm{TM}}\left(\mathrm{m}^{3} / \mathrm{rev}\right)$ & $8.3 \times 10^{-6}$ & $8 \times 10^{-6}$ \\
$P_{\text {gas }}(\mathrm{Pa})$ & $9 \times 10^{6}$ & $9.4 \times 10^{6}$ \\
\hline
\end{tabular}

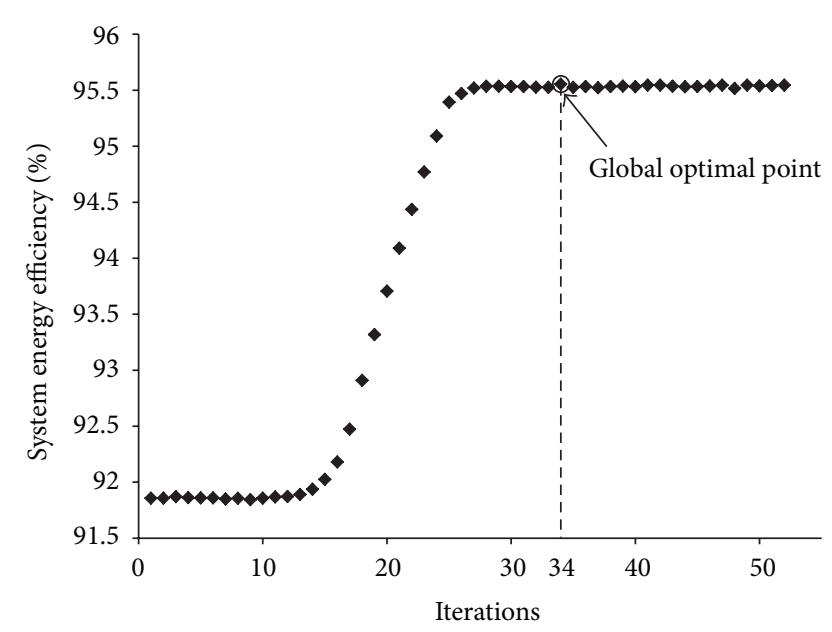

FIGURE 10: System energy efficiency versus iterations.

such as accumulator size $-0.008 \mathrm{~m}^{3}$, precharge pressure of accumulator-9.4 $\times 10^{6} \mathrm{~N} / \mathrm{m}^{2}$, volumetric displacement of master hydraulic pump-1.4 $\times 10^{-5} \mathrm{~m}^{3} / \mathrm{rev}$, and volumetric displacement of traction hydraulic motor $-8 \times 10^{-6} \mathrm{~m}^{3} / \mathrm{rev}$. It also tabulates the initial values before optimization of the design variables. The optimal design variables values in the design ID-34 was inputted into the system model and system simulation is repeated.

Figure 11 shows the trend of total input energy and output energy of the system (before and after optimization of the system) over the period of driving cycle. The variations of energy with cycle time after optimization are higher than those before optimization of system parameters. It can be observed that $14705 \mathrm{~kJ}$ of output energy is delivered by the optimal system for the given input energy of $14063 \mathrm{~kJ}$ when compared to $8646 \mathrm{~kJ}$ of output energy for the corresponding input energy of $9389 \mathrm{~kJ}$ in the nonoptimal system. However, the system energy efficiency after optimization has increased by $3.6 \%$ from the initial value of $92 \%$ before optimization to $95.6 \%$ after optimization. Figure 12 shows the change in instantaneous input power and output power of the system. It was observed that, the trend of instantaneous output power

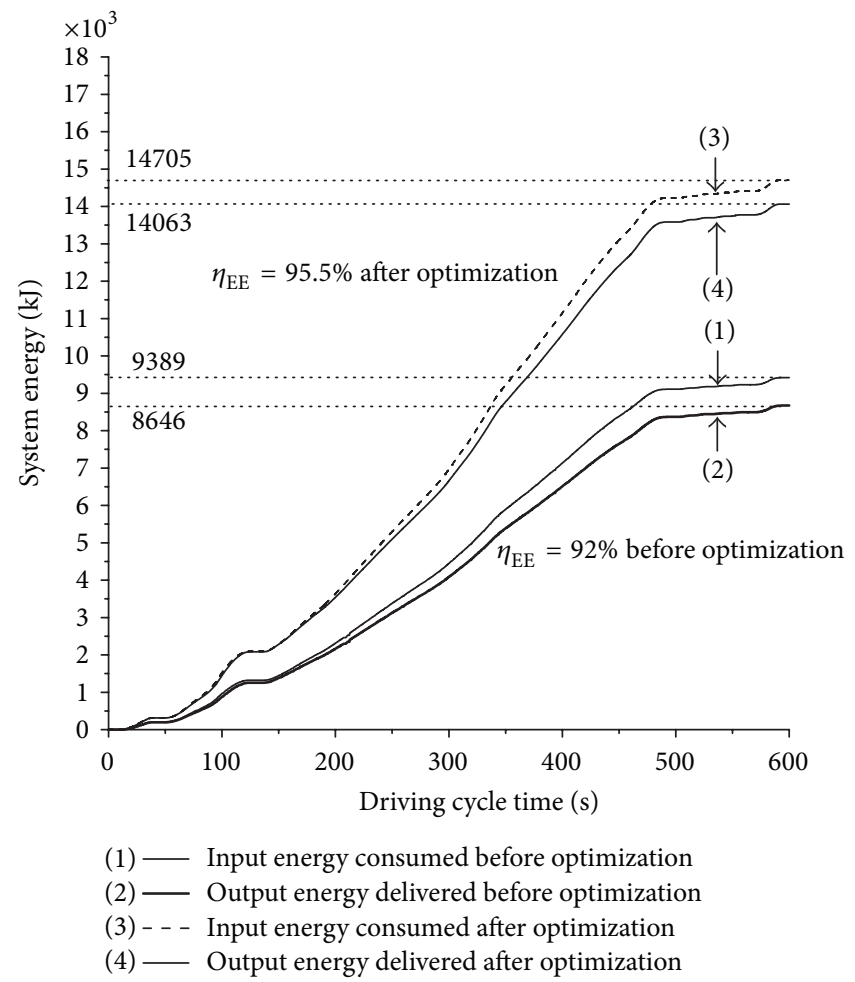

FIgURE 11: System energy before and after optimization.

in the optimal system as shown in Figure 12(d) after optimization has improved when compared to the output power in nonoptimal system as shown in Figure 12(b). Similarly, instantaneous input power of optimal system as shown in Figure 12(c) is higher than input power in the nonoptimal system as shown in Figure 12(a) for the corresponding supplied input power.

\section{Conclusion}

In this paper, a unified power bond graph modeling approach has been used to model the dynamics of a series hydraulic hybrid system. An initial comparison of the proposed system behavior against a reference configuration of series hybrid from literature showed a substantial improvement in the output power delivered. Simulation results explain various modes of operation in system and also describe the dynamic response of hydropneumatic accumulator, prime mover, and system output speed. The optimization problem is formulated for maximizing the system energy efficiency to obtain the 


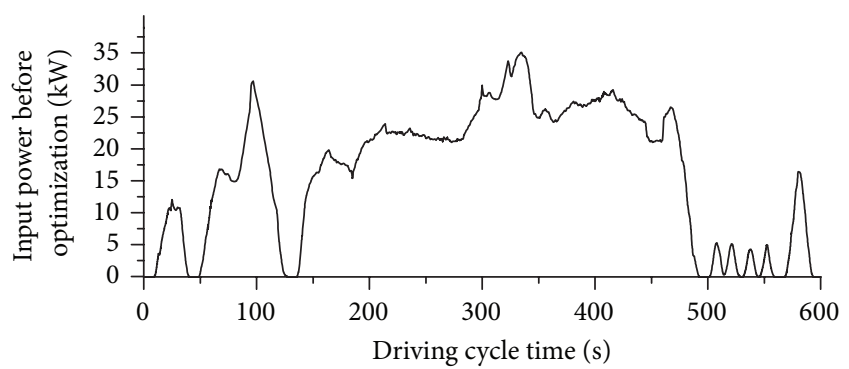

(a)

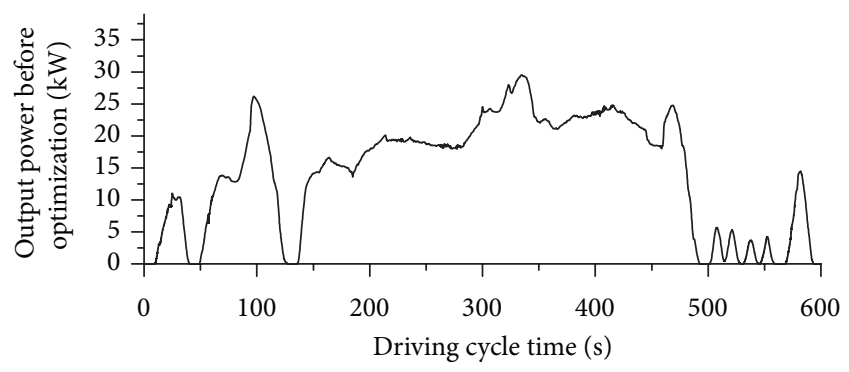

(b)

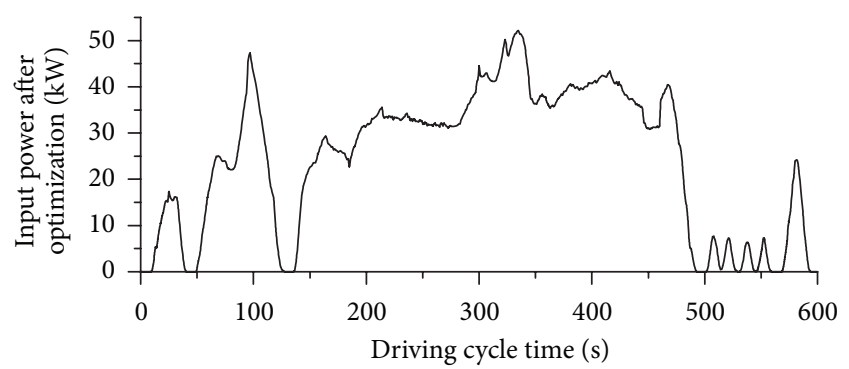

(c)

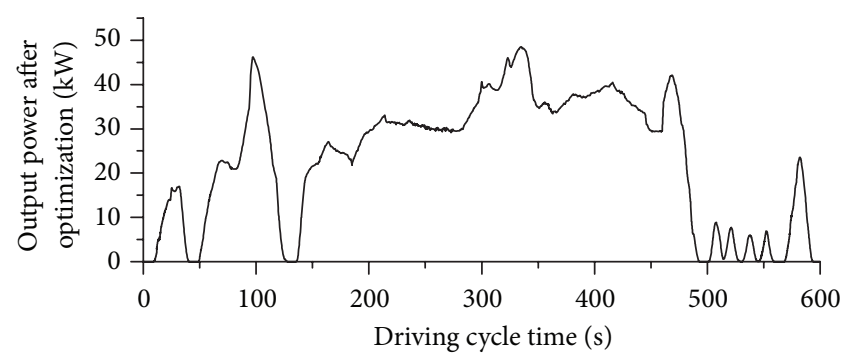

(d)

FIGURE 12: System power versus time.

optimal key system parameters. Optimization of key component sizes in series hydraulic hybrid system is carried out. Optimization results show that system energy efficiency has increased by $3.6 \%$ (increased from $92 \%$ to $95.6 \%$ ) when compared to system output energy in nonoptimized system. Thus, system is designed by parameter optimization based on the composite objective function. This procedure leads to better performance and indirectly leads to better fuel efficiency.

\section{Appendix}

The detailed derivation of equations for input power and output power of the system is derived as follows.
Input Power $\left(P_{\mathrm{IN}}\right)$. The input power of the system is a function of torque at prime mover and speed input to the system is shown as follows:

$$
P_{\mathrm{IN}}=T_{\mathrm{PM}} \omega_{\mathrm{PM}} \cdot
$$

From (1) and (2), the torque at the prime mover is derived as follows:

$$
T_{\mathrm{PM}}=D_{\mathrm{MP}} P_{\mathrm{MP}}+B_{\mathrm{MP}} \frac{q_{\mathrm{mp}}}{D_{\mathrm{MP}}} .
$$

Substituting (4) in (A.2) gives the torque at prime mover in terms of actual flow rate at master hydraulic pump as follows:

$$
T_{\mathrm{PM}}=D_{\mathrm{MP}} P_{\mathrm{MP}}+\frac{B_{\mathrm{MP}}}{D_{\mathrm{MP}}}\left(q_{1}+q_{\mathrm{lp}}+q_{\mathrm{cp}}\right) .
$$

From (5) and (A.3), (A.4) can be written as

$$
T_{\mathrm{PM}}=D_{\mathrm{MP}} P_{\mathrm{MP}}+\frac{B_{\mathrm{MP}}}{D_{\mathrm{MP}}}\left(q_{1}+\frac{P_{\mathrm{MP}}}{R_{\mathrm{LP}}}+\frac{V_{01}}{B} \frac{d P_{\mathrm{MP}}}{d t}\right) .
$$

Substituting (7) in (A.4) gives the torque at prime mover in terms of $P_{2}, q_{4}$, and $R_{H 1}$ as follows:

$$
\begin{aligned}
T_{\mathrm{PM}}= & D_{\mathrm{MP}}\left(R_{H 1} q_{2}+P_{2}+\Delta P_{4}\right) \\
& +\frac{B_{\mathrm{MP}}}{D_{\mathrm{MP}}}\left(q_{1}+\frac{\left(R_{H 1} q_{2}+P_{2}+\Delta P_{4}\right)}{R_{\mathrm{LP}}}+\frac{V_{01}}{B} \frac{d P_{\mathrm{MP}}}{d t}\right) .
\end{aligned}
$$

From (11) and (A.5), (A.6) can be written as

$$
\begin{aligned}
& T_{\mathrm{PM}}= D_{\mathrm{MP}}\left(R_{H 1} q_{2}+P_{2}+\Delta P_{4}\right) \\
&+\frac{B_{\mathrm{MP}}}{D_{\mathrm{MP}}}\left(q_{3}+\left[\left(\Delta P_{5}-P_{\mathrm{set}}\right) G_{0}+G_{\mathrm{prv}} \Delta P_{5}\right]-q_{\mathrm{ch}}\right. \\
&\left.+\frac{\left(R_{H 1} q_{2}+P_{2}+\Delta P_{4}\right)}{R_{\mathrm{LP}}}+\frac{V_{01}}{B} \frac{d P_{\mathrm{MP}}}{d t}\right) .
\end{aligned}
$$

The following equation can be written by substituting (12), (15), and (16) in (A.6):

$$
\begin{aligned}
& T_{\mathrm{PM}}=D_{\mathrm{MP}}\left(R_{H 1} q_{2}+P_{H 2}+\frac{T_{\mathrm{TM}}}{D_{\mathrm{TM}}}+\Delta P_{4}\right) \\
&+\frac{B_{\mathrm{MP}}}{D_{\mathrm{MP}}}\left(q_{\mathrm{tm}}+\frac{P_{3}}{R_{\mathrm{LM}}}+\frac{V_{02}}{B} \frac{d P_{3}}{d t}+\frac{V_{01}}{B} \frac{d P_{\mathrm{MP}}}{d t}\right. \\
&+\left[\left(\Delta P_{5}-P_{\mathrm{set}}\right) G_{0}+G_{\mathrm{prv}} \Delta P_{5}\right]-q_{\mathrm{ch}} \\
&\left.+\frac{\left(R_{H 1} q_{2}+P_{H 2}+T_{\mathrm{TM}} / D_{\mathrm{TM}}+\Delta P_{4}\right)}{R_{\mathrm{LP}}}\right) .
\end{aligned}
$$

Finally, the input power to the system is derived as a function of system parameters as shown in (A.8), which corresponds to (39):

$$
P_{\mathrm{IN}}=\omega_{\mathrm{PM}} D_{\mathrm{MP}}\left(R_{H 1} q_{2}+P_{H 2}+\frac{T_{\mathrm{TM}}}{D_{\mathrm{TM}}}+\Delta P_{4}\right)
$$




$$
\begin{aligned}
+\frac{\omega_{\mathrm{PM}} B_{\mathrm{MP}}}{D_{\mathrm{MP}}}( & q_{\mathrm{tm}}+\frac{P_{3}}{R_{\mathrm{LM}}}+\frac{V_{02}}{B} \frac{d P_{3}}{d t}+\frac{V_{01}}{B} \frac{d P_{\mathrm{MP}}}{d t} \\
+ & {\left[\left(\Delta P_{5}-P_{\mathrm{set}}\right) G_{0}+G_{\mathrm{prv}} \Delta P_{5}\right]-q_{\mathrm{ch}} } \\
+ & \left.\frac{\left(R_{H 1} q_{2}+P_{\mathrm{H} 2}+T_{\mathrm{TM}} / D_{\mathrm{TM}}+\Delta P_{4}\right)}{R_{\mathrm{LP}}}\right) .
\end{aligned}
$$

Output Power $\left(P_{\text {OUT }}\right)$. The output power of the system is a function of torque at prime mover and speed input to the system as shown below:

$$
P_{\mathrm{OUT}}=T_{\mathrm{TM}} \omega_{\mathrm{TM}}
$$

At transformer element TF: $D_{\mathrm{TM}}$, torque at traction motor can be written as

$$
T_{\mathrm{TM}}=D_{\mathrm{TM}} P_{\mathrm{TM}} \cdot
$$

Substituting (13) in (A.10) would arrive at

$$
T_{\mathrm{TM}}=D_{\mathrm{TM}}\left(P_{2}-R_{H_{2}} q_{3}\right) .
$$

From (8) and (A.9), (A.12) can be written as

$$
T_{\mathrm{TM}}=D_{\mathrm{TM}}\left(P_{\mathrm{MP}}-R_{\mathrm{H}_{1}} q_{2}-\Delta P_{42}-R_{\mathrm{H}_{2}} q_{3}\right) .
$$

Substituting (6) in (A.12) would arrive at (A.13)

$$
T_{\mathrm{TM}}=D_{\mathrm{TM}}\left(\frac{T_{\mathrm{MP}}}{D_{\mathrm{MP}}}-R_{H_{1}} q_{2}-\Delta P_{42}-R_{H_{2}} q_{3}\right) .
$$

Speed of the traction motor in the transformer element TF: $D_{\mathrm{TM}}$ can be written as

$$
\omega_{\mathrm{TM}}=\frac{q_{\mathrm{tm}}}{D_{\mathrm{TM}}} .
$$

Substituting (15) in (A.14) would arrive at

$$
\begin{aligned}
\omega_{\mathrm{TM}}=\frac{1}{D_{\mathrm{TM}}}( & q_{2}-q_{\mathrm{ch}}-\left(\Delta P_{5}-P_{\mathrm{set}}\right) G_{0} \\
& \left.\quad-G_{\mathrm{PRV}} \Delta P_{5}-\frac{P_{3}}{R_{\mathrm{LM}}}-\frac{V_{02}}{B} \frac{d P_{3}}{d t}\right) .
\end{aligned}
$$

From (5), (6), (36), and (A.15), the speed of the traction motor shaft can be written in terms of input prime mover speed as

$$
\begin{aligned}
\omega_{\mathrm{TM}}=\frac{1}{D_{\mathrm{TM}}}( & D_{\mathrm{MP}} \omega_{\mathrm{MP}}-\frac{T_{\mathrm{MP}}}{D_{\mathrm{MP}} R_{\mathrm{LP}}}-\frac{V_{01}}{B} \frac{d P_{\mathrm{MP}}}{d t} \\
& -\frac{V_{02}}{B} \frac{d P_{3}}{d t}-\frac{T_{\mathrm{TM}}}{D_{\mathrm{TM}} R_{\mathrm{LM}}} \\
& -P_{0 \text { gas }}\left(V_{\text {0gas }}\right)^{\gamma} \frac{d P_{\text {gas }}}{d t} \\
& \left.-\left(\Delta P_{5}-P_{\text {set }}\right) G_{0}-G_{\mathrm{PRV}} \Delta P_{5}\right) .
\end{aligned}
$$

Finally, the output power to the system is derived as a function of system parameters as shown in (A.17), which corresponds to $(40)$ :

$$
\begin{aligned}
P_{\mathrm{OUT}}= & \left(\frac{T_{\mathrm{MP}}}{D_{\mathrm{MP}}}-R_{\mathrm{H}_{1}} q_{2}-\Delta P_{42}-R_{\mathrm{H}_{2}} q_{3}\right) \\
& \times\left(D_{\mathrm{MP}} \omega_{\mathrm{MP}}-\frac{T_{\mathrm{MP}}}{D_{\mathrm{MP}} R_{\mathrm{LP}}}-\frac{V_{01}}{B} \frac{d P_{\mathrm{MP}}}{d t}\right. \\
& -\frac{V_{02}}{B} \frac{d P_{3}}{d t}-\frac{T_{\mathrm{TM}}}{D_{\mathrm{TM}} R_{\mathrm{LM}}} \\
& -P_{0 \mathrm{gas}}\left(V_{0 \mathrm{gas}}\right)^{\gamma} \frac{d P_{\mathrm{gas}}}{d t} \\
& \left.-\left(\Delta P_{5}-P_{\text {set }}\right) G_{o}-G_{\mathrm{PRV}} \Delta P_{5}\right) .
\end{aligned}
$$

\section{Nomenclature}

$\Delta P_{1}:$ Pressure drop across NRV $1(\mathrm{~Pa})$

$\Delta P_{2}$ : Pressure drop across NRV $2(\mathrm{~Pa})$

$\Delta P_{3}$ : Pressure drop across proportional control valve $(\mathrm{Pa})$

$\Delta P_{4}:$ Pressure drop across NRV $3(\mathrm{~Pa})$

$\Delta P_{5}:$ Pressure drop across pressure relief valve $(\mathrm{Pa})$

A: Area of orifice in proportional control valve $\left(\mathrm{m}^{2}\right)$

$a_{s}: \quad$ Vehicle active front area $\left(\mathrm{m}^{2}\right)$

$B$ : $\quad$ Effective bulk modulus of hydraulic oil $(\mathrm{Pa})$

$B_{\mathrm{MP}}$ : Master pump mechanical efficiency friction coefficient ( $\mathrm{Nm} \mathrm{s}$ )

$B_{\mathrm{RP}}$ : Regeneration pump mechanical efficiency friction coefficient ( $\mathrm{Nm} \mathrm{s}$ )

$B_{\mathrm{TM}}$ : Traction motor mechanical efficiency friction coefficient (Nm s)

$C_{A}$ : Compliance effect in hydropneumatic accumulator $\left(\mathrm{m}^{3} / \mathrm{Pa}\right)$

$C_{d}: \quad$ Coefficient of discharge (-)

$C_{\mathrm{MP}}$ : Compliance effect in master pump $\left(\mathrm{m}^{3} / \mathrm{Pa}\right)$

$C_{\mathrm{RP}}$ : Compliance effect in regeneration pump $\left(\mathrm{m}^{3} / \mathrm{Pa}\right)$

$C_{\mathrm{TM}}$ : Compliance effect in traction motor $\left(\mathrm{m}^{3} / \mathrm{Pa}\right)$

$C_{x}: \quad$ Air penetration coefficient (-)

$D_{\mathrm{MP}}$ : Volumetric displacement of master pump $\left(\mathrm{m}^{3} / \mathrm{rev}\right)$

$d_{\text {rim }}:$ Diameter of the wheel (m)

$D_{\mathrm{RP}}$ : Volumetric displacement of regeneration pump $\left(\mathrm{m}^{3} / \mathrm{rev}\right)$

$D_{\mathrm{TM}}$ : Volumetric displacement of traction motor $\left(\mathrm{m}^{3} / \mathrm{rev}\right)$

$F_{\mathrm{AD}}$ : Aerodynamic resistance force $(\mathrm{N})$

$F_{\mathrm{RF}}$ : Rolling resistance force $(\mathrm{N})$

$F_{\mathrm{VD}}$ : Resistance force due to vehicle dynamics $(\mathrm{N})$ 
$F_{\mathrm{VM}}$ : Resistant force due to vehicle moment of inertia $(\mathrm{N})$

g: Acceleration due to gravity $\left(\mathrm{m} / \mathrm{s}^{2}\right)$

$G_{\mathrm{LP}}$ : Conductance of proportional control valve $\left(\mathrm{m}^{3} / \mathrm{Pa}-\mathrm{s}\right)$

$G_{0}$ : Conductance of open pressure relief valve $\left(\mathrm{m}^{3} / \mathrm{Pa}-\mathrm{s}\right)$

$G_{\mathrm{PRV}}$ : Conductance of closed pressure relief valve $\left(\mathrm{m}^{3} / \mathrm{Pa}-\mathrm{s}\right)$

$H: \quad$ Height of the tire $(\mathrm{m})$

$J_{\mathrm{VM}}$ : Moment of inertia in vehicle wheel $\left(\mathrm{kgm}^{3}\right)$

$J_{w}: \quad$ Inertia of the wheel $\left(\mathrm{kg}-\mathrm{m}^{2}\right)$

$m$ : Mass of the vehicle $(\mathrm{kg})$

$m_{\text {veh }}$ : Total mass of the vehicle $(\mathrm{kg})$

$\mathrm{P}_{2}$ : $\quad$ Pressure at zero junction-2 end of hydraulic hose $1(\mathrm{~Pa})$

$P_{3}$ : $\quad$ Pressure at one junction- 4 end of hydraulic hose $2(\mathrm{~Pa})$

$P_{A}: \quad$ Pressure of accumulator at any time $(\mathrm{Pa})$

$P_{C}$ : Pressure of accumulator during regeneration $(\mathrm{Pa})$

$P_{\mathrm{CH}}:$ Pressure at outlet port of NRV $1(\mathrm{~Pa})$

$P_{\mathrm{CL} 1}:$ Cracking pressure of NRV $1(\mathrm{~Pa})$

$P_{\mathrm{CL} 2}$ : Cracking pressure of NRV $2(\mathrm{~Pa})$

$P_{D}: \quad$ Pressure of accumulator during discharge $(\mathrm{Pa})$

$P_{H 1}$ : Pressure drop across hydraulic hose 1 (Pa)

$P_{\mathrm{H} 2}$ : Pressure drop across hydraulic hose 2 (Pa)

$P_{H 3}:$ Pressure drop across hydraulic hose 3 (Pa)

$P_{\mathrm{MP}}$ : Pressure at outlet port of master pump (Pa)

$P_{\text {ogas }}:$ Precharge pressure of gas in the accumulator $(\mathrm{Pa})$

$P_{\mathrm{PV}}:$ Pressure at outlet port of proportional control valve $(\mathrm{Pa})$

$P_{\mathrm{RP}}: \quad$ Pressure at regeneration pump outlet $(\mathrm{Pa})$

$P_{\text {set }}$ : Set pressure of accumulator at any time (Pa)

$P_{\mathrm{TM}}:$ Pressure at inlet port of traction motor $(\mathrm{Pa})$

$q_{1}: \quad$ Actual flow rate from master pump $\left(\mathrm{m}^{3} / \mathrm{s}\right)$

$q_{2}$ : Flow rate at zero junction-2 end of hydraulic hose $1\left(\mathrm{~m}^{3} / \mathrm{s}\right)$

$q_{3}$ : Flow rate to the traction motor $\left(\mathrm{m}^{3} / \mathrm{s}\right)$

$q_{4}$ : Actual flow rate to regeneration pump $\left(\mathrm{m}^{3} / \mathrm{s}\right)$

$q_{a}: \quad$ Flow rate at inlet port of accumulator $\left(\mathrm{m}^{3} / \mathrm{s}\right)$

$q_{c}: \quad$ Flow rate into the accumulator $\left(\mathrm{m}^{3} / \mathrm{s}\right)$

$q_{\mathrm{ch}}$ : Flow rate from NRV $1\left(\mathrm{~m}^{3} / \mathrm{s}\right)$

$q_{\mathrm{cm}}$ : Flow rate due to compressibility in traction motor $\left(\mathrm{m}^{3} / \mathrm{s}\right)$ $q_{\mathrm{cp}}: \quad$ Flow loss due to compressibility of oil in master pump $\left(\mathrm{m}^{3} / \mathrm{s}\right)$

$q_{\mathrm{cr}}$ : Flow loss due to compressibility of oil in regeneration pump $\left(\mathrm{m}^{3} / \mathrm{s}\right)$

$q_{d}: \quad$ Flow rate from the accumulator during discharge $\left(\mathrm{m}^{3} / \mathrm{s}\right)$

$q_{\mathrm{lm}}$ : Flow rate due to leakage in traction motor $\left(\mathrm{m}^{3} / \mathrm{s}\right)$

$q_{\mathrm{lp}}$ : $\quad$ Flow loss due to leakage in master pump $\left(\mathrm{m}^{3} / \mathrm{s}\right)$

$q_{1 \mathrm{r}}$ : $\quad$ Flow loss due to leakage in regeneration pump $\left(\mathrm{m}^{3} / \mathrm{s}\right)$

$q_{\mathrm{mp}}:$ Ideal flow rate of master pump $\left(\mathrm{m}^{3} / \mathrm{s}\right)$

$q_{\text {prv }}$ : Flow rate through pressure relief valve $\left(\mathrm{m}^{3} / \mathrm{s}\right)$

$q_{\mathrm{pv}}: \quad$ Flow rate at outlet port of proportional control valve $\left(\mathrm{m}^{3} / \mathrm{s}\right)$

$q_{\mathrm{rp}}$ : Ideal flow rate of regeneration pump $\left(\mathrm{m}^{3} / \mathrm{s}\right)$

$q_{\mathrm{tm}}$ : Actual flow rate to traction motor $\left(\mathrm{m}^{3} / \mathrm{s}\right)$

$R_{\mathrm{AD}}$ : Aerodynamic resistance (Ns/m)

$R_{H 1}$ : Line resistance in hydraulic hose 1 $\left(\mathrm{Pa}-\mathrm{s} / \mathrm{m}^{3}\right)$

$R_{H 2}$ : Line resistance in hydraulic hose 2 $\left(\mathrm{Pa}-\mathrm{s} / \mathrm{m}^{3}\right)$

$R_{H_{3}}$ : Line resistance in hydraulic hose 3 $\left(\mathrm{Pa}-\mathrm{s} / \mathrm{m}^{3}\right)$

$R_{\mathrm{LM}}$ : Traction motor internal leakage resistance $\left(\mathrm{Pa}-\mathrm{s} / \mathrm{m}^{3}\right)$

$R_{\mathrm{LP}}$ : Master pump internal leakage resistance $\left(\mathrm{Pa}-\mathrm{s} / \mathrm{m}^{3}\right)$

$R_{\mathrm{LR}}$ : Regeneration pump internal leakage resistance $\left(\mathrm{Pa}-\mathrm{s} / \mathrm{m}^{3}\right)$

$R_{N 1}$ : Resistance at NRV $1\left(\mathrm{~Pa}-\mathrm{s} / \mathrm{m}^{3}\right)$

$R_{N 2}:$ Resistance at NRV $2\left(\mathrm{~Pa}-\mathrm{s} / \mathrm{m}^{3}\right)$

$R_{N_{3}}$ : Resistance at NRV $3\left(\mathrm{~Pa}-\mathrm{s} / \mathrm{m}^{3}\right)$

$R_{\mathrm{PRV}}$ : Resistance offered by pressure relief valve $\left(\mathrm{Pa}-\mathrm{s} / \mathrm{m}^{3}\right)$

$R_{\mathrm{RF}}:$ Rolling friction resistance (Ns/m)

$r_{w}$ : $\quad$ Radius of the wheel $(\mathrm{m})$

$T_{\mathrm{BMP}}$ : Torque loss due to mechanical friction in master pump $(\mathrm{Nm})$

$T_{\mathrm{BRP}}$ : Torque loss due to mechanical friction in regeneration pump $(\mathrm{Nm})$

$T_{\text {BTM }}$ : Torque loss due to mechanical friction in traction motor $(\mathrm{Nm})$

$T_{\mathrm{MP}}$ : Torque at master pump (Nm)

$T_{\mathrm{PM}}$ : Torque at prime mover $(\mathrm{Nm})$

$T_{\mathrm{RP}}$ : Torque at regeneration pump shaft $(\mathrm{Nm})$

$T_{\mathrm{TM}}$ : Torque at traction hydraulic motor shaft $(\mathrm{Nm})$

$T_{\mathrm{VD}}$ : Torque applied due to vehicle dynamics (Nm)

$V_{\text {ogas }}:$ Initial volume of gas in the accumulator $\left(\mathrm{m}^{3}\right)$ 
$V_{01}$ : Volume of oil under pressure at zero junction-1 $\left(\mathrm{m}^{3}\right)$

$V_{02}$ : Volume of oil under pressure at zero junction-3 $\left(\mathrm{m}^{3}\right)$

$V_{03}$ : Volume of oil under pressure at zero junction- $4\left(\mathrm{~m}^{3}\right)$

$V_{V}$ : Linear velocity of the vehicle $(\mathrm{m} / \mathrm{s})$

$V_{\text {wind }}$ : Input wind velocity $(\mathrm{m} / \mathrm{s})$

$w$ : Width of the tire $(\mathrm{m})$

$\alpha: \quad$ Slope of the road (degrees)

$\gamma: \quad$ Isentropic index of gas (-)

$\rho: \quad$ Density of hydraulic oil $\left(\mathrm{kg} / \mathrm{m}^{3}\right)$

$\rho_{\text {air }}: \quad$ Density of the air $\left(\mathrm{Kg} / \mathrm{m}^{3}\right)$

$\omega_{\mathrm{MP}}:$ Speed at master pump shaft $(\mathrm{rad} / \mathrm{s})$

$\omega_{\mathrm{PM}}$ : Speed of prime mover $(\mathrm{rad} / \mathrm{s})$

$\omega_{\mathrm{TM}}$ : Speed at traction hydraulic motor shaft $(\mathrm{rad} / \mathrm{s})$

\section{Conflict of Interests}

The authors declare that there is no conflict of interests regarding the publication of this paper.

\section{References}

[1] A. E. Fuhs, Hybrid Vehicles and the Future of Personal Transportation, CRC Press, 2009.

[2] E. Karden, S. Ploumen, B. Fricke, T. Miller, and K. Snyder, "Energy storage devices for future hybrid electric vehicles," Journal of Power Sources, vol. 168, no. 1, pp. 2-11, 2007.

[3] J. Liu and H. Peng, "A systematic design approach for two planetary gear split hybrid vehicles," Vehicle System Dynamics, vol. 48, no. 11, pp. 1395-1412, 2010.

[4] P. Shakouri, A. Ordys, P. Darnell, and P. Kavanagh, "Fuel efficiency by coasting in the vehicle," International Journal of Vehicular Technology, vol. 2013, Article ID 391650, 14 pages, 2013.

[5] C. Shen, P. Shan, and T. Gao, "A comprehensive overview of hybrid electric vehicles," International Journal of Vehicular Technology, vol. 2011, Article ID 571683, 7 pages, 2011.

[6] K. E. Rydberg, "Energy efficient hydraulic hybrid drives," in Proceedings of the 11th Scandinavian International Conference on Fluid Power (SICFP '09), pp. 1-14, Linkoping, June 2009.

[7] E. Dinçmen and B. A. Güvenç, "A control strategy for parallel hybrid electric vehicles based on extremum seeking," Vehicle System Dynamics, vol. 50, no. 2, pp. 199-227, 2012.

[8] C. Ji, Y. Zhu, C. Liang, and X. Liu, "Simulation study on the operating characteristics of a hybrid hydraulic passenger car with a power split transmission," International Journal of Vehicle System Dynamics, vol. 51, no. 10, pp. 1518-1532, 2013.

[9] J. D. Van de Ven, M. W. Olson, and P. Y. Li, "Development of hydro-mechanical hydraulic hybrid drive with independent wheel torque control for an urban passenger vehicle," in Proceedings of the International Fluid Power Exposition, pp. 11-15, Las Vegas, Nev, USA, March 2008.

[10] Y. J. Kim and Z. Filipi, "Series hydraulic hybrid propulsion for a light truck- optimizing the thermostatic power management," SAE Transactions, Journal of Engines, vol. 116, Article ID 200724-0080, pp. 1597-1609, 2007.
[11] B. Wu, C.-C. Lin, Z. Filipi, H. Peng, and D. Assanis, "Optimal power management for a hydraulic hybrid delivery truck," Vehicle System Dynamics, vol. 42, no. 1-2, pp. 23-40, 2004.

[12] Y. J. Kim and Z. Filipi, "Simulation study of a series hydraulic hybrid propulsion system for a light truck," Society of Automobile Engineers Paper 2007-01-4151, University of Michigan, 2007.

[13] R. Ramakrishnan, S. S. Hiremath, and M. Singaperumal, "Power bond graph modeling of series hydraulic hybrid system," in Proceedings of the International Conference on Fluid Mechanics and Fluid Power, paper 608, pp. 1-8, IIT Madras, 2010.

[14] F. T. Elder and D. R. Otis, "Simulation of a hydraulic hybrid powertrain," American Society of Mechanical Engineers, Article ID 73-ICT-50, pp. 1-6, 1973.

[15] Z. Filipi and Y. J. Kim, "Hydraulic hybrid propulsion for heavy vehicles: combining the simulation and engine-in-theloop techniques to maximize the fuel economy and emission benefits," Oil and Gas Science and Technology, vol. 65, no. 1, pp. 155-178, 2010.

[16] R. Ramakrishnan, S. S. Hiremath, and M. Singaperumal, "Theoretical investigations on the effect of system parameters in series hydraulic hybrid system with hydrostatic regenerative braking," The Journal of Mechanical Science and Technology, vol. 26, no. 5, pp. 1321-1331, 2012.

[17] P. Wu, N. Luo, F. J. Fronczak, and N. H. Beachley, "Fuel economy and operating characteristics of hydro-pneumatic energy storage automobile," Tech. Rep. 851678, Society of Automobile Engineers, 1985.

[18] D. Sinoquet, G. Rousseau, and Y. Milhau, "Design optimization and optimal control for hybrid vehicles," Optimization and Engineering, vol. 12, no. 1-2, pp. 199-213, 2011.

[19] S. S. Hiremath, R. Ramakrishnan, and M. Singaperumal, "Optimization of process parameters in series hydraulic hybrid system," in Proceedings of 13th Scandinavian Conference on Fluid Power, pp. 199-205, Linkoping University, 2013.

[20] R. E. Kruse and T. A. Huls, "Development of the federal urban driving schedule," SAE Paper 730553, Society of Automobile Engineers, 1973.

[21] M. Singaperumal and S. S. Hiremath, "Investigations on actuator dynamics through theoretical and finite element approach," Mathematical Problems in Engineering, vol. 2010, Article ID 191898, 22 pages, 2010.

[22] G. Pease and J. M. Henderson, "Simulation of a hydraulic hybrid vehicle using bond graphs," Journal of Mechanisms, Transmissions, and Automation in Design, vol. 110, no. 3, pp. 365-369, 1988.

[23] W. Borutzky, "Bond graph modelling and simulation of multidisciplinary systems-an introduction," Simulation Modelling Practice and Theory, vol. 17, no. 1, pp. 3-21, 2009.

[24] B. W. Barnard and P. Dransfield, "Predicting response of a proposed hydraulic control system using bond graphs," Transactions of the ASME Journal of Dynamic Systems, Measurement and Control, vol. 99, no. 1, pp. 1-8, 1977.

[25] D. Hrovat and W. E. Tobler, "Bond graph modeling of automotive power trains," Journal of the Franklin Institute, vol. 328, no. 5-6, pp. 623-662, 1991.

[26] P. Dransfield, "Using bond graph in simulating an ElectroHydraulic System," Journal of the Franklin Institute, vol. 308, no. 3, pp. 173-184, 1979.

[27] M. Filippa, C. Mi, J. Shen, and R. C. Stevenson, "Modeling of a hybrid electric vehicle powertrain test cell using bond graphs," IEEE Transactions on Vehicular Technology, vol. 54, no. 3, pp. 837-845, 2005. 
[28] Q. Zhao and F. Gao, "Bond graph modeling of hydraulic six-degree-of-freedom motion simulator," Proceedings of the Institution of Mechanical Engineers C, vol. 226, no. 12, pp. 28872901, 2012.

[29] W. Borutzky, B. Barnard, and J. U. Thoma, "Describing bond graph models of hydraulic components in Modelica," Mathematics and Computers in Simulation, vol. 53, no. 4-6, pp. 381387,2000 .

[30] S.-J. Lee and P.-H. Chang, "Modeling of a hydraulic excavator based on bond graph method and its parameter estimation," Journal of Mechanical Science and Technology, vol. 26, no. 1, pp. 195-204, 2012.

[31] C. Kleijn, "Getting Started with 20-sim 4. 1. 20-Sim corporation Pvt," 2009, http://www.20sim.com/downloads/files/ 20sim41GettingStartedManual.pdf.

[32] K. Dasgupta, "Analysis of a hydrostatic transmission system using low speed high torque motor," Mechanism and Machine Theory, vol. 35, no. 10, pp. 1481-1499, 2000.

[33] J. D. Head and M. C. Zerner, "A Broyden-Fletcher-GoldfarbShanno optimization procedure for molecular geometries," International Journal of Chemical Physics Letters, vol. 122, no. 3, pp. 264-270, 1985. 

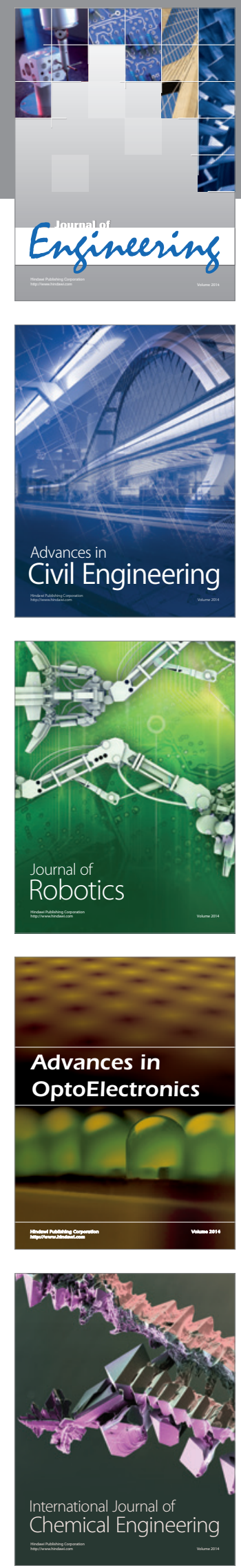

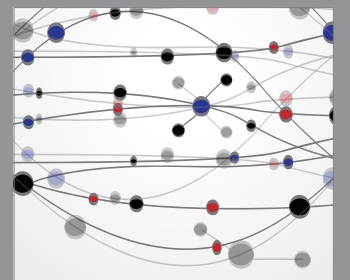

The Scientific World Journal
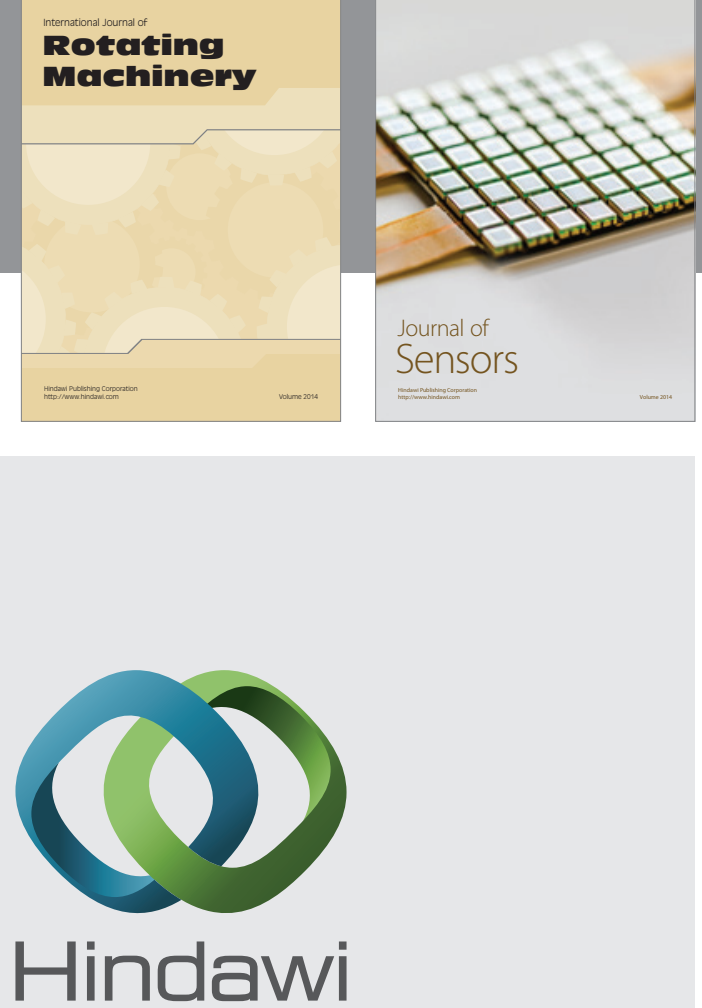

Submit your manuscripts at http://www.hindawi.com
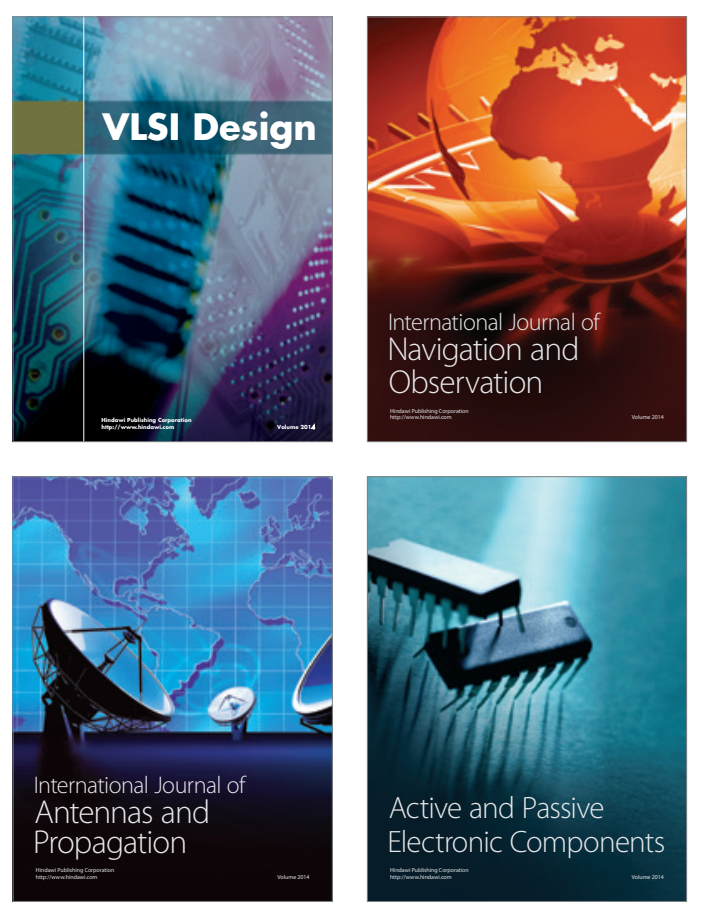
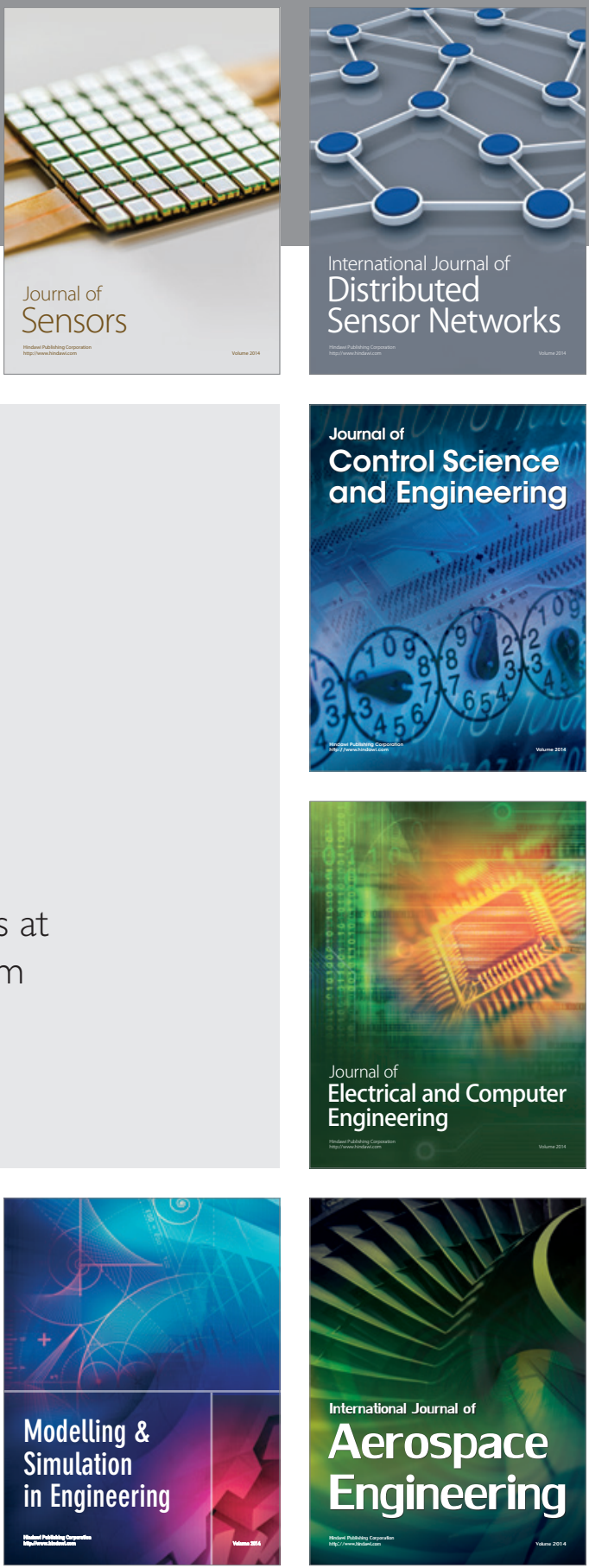

Journal of

Control Science

and Engineering
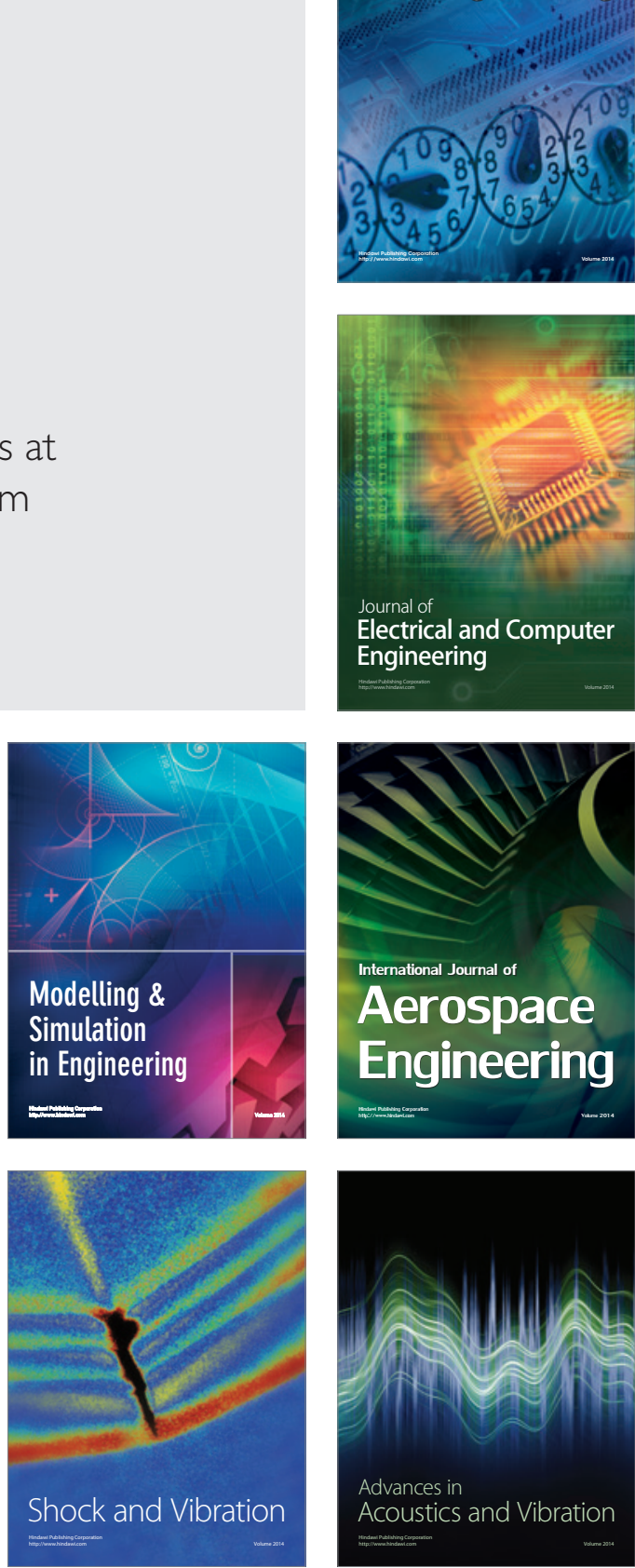